\title{
ICTIOFAUNA DEL MIOCENO INFERIOR DE LA LOCALIDAD DE PACUARE DE TRES EQUIS, FORMACIÓN RÍO BANANO, PROVINCIA DE CARTAGO, COSTA RICA, Y DESCRIPCIÓN DE UN NUEVO GÉNERO Y UNA NUEVA ESPECIE DE SCARIDAE
}

\section{LOWER MIOCENE ICHTHYOFAUNA FROM THE LOCALITY OF PACUARE DE TRES EQUIS, RÍO BANANO FORMATION, CARTAGO PROVINCE, COSTA RICA AND DESCRIPTION OF A NEW GENUS AND SPECIES OF SCARIDAE}

\author{
César A. Laurito ${ }^{1 \& 2^{*}}$, Cristian Calvo ${ }^{3}$, Ana L. Valerio ${ }^{4}$, \\ Alejandro Calvo ${ }^{3} \&$ Rafael Chacón ${ }^{4}$ \\ ${ }^{1}$ INA, Instituto Nacional de Aprendizaje \\ ${ }^{2}$ Investigador asociado-Departamento de Historia Natural, Museo Nacional de Costa Rica \\ ${ }^{3}$ Finca Sacramento, Pacuare de Tres Equis Turrialba \\ ${ }^{4}$ Departamento de Historia Natural, Museo Nacional de Costa Rica. \\ Apdo.postal 749-1000, San José \\ * Autor para contacto: cesarlaurito@ice.co.cr
}

(Recibido: 20/01/2014 ; aceptado: 13/06/2014)

\begin{abstract}
A studied of the Lower Miocene fish fauna of the Pacuare de Tres Equis locality is made. In this area it is recorded 8 genera of sharks: Heptranchias, Megaselachus, Isurus, Carcharias, Mitsukurina, Hemipristis, Negaprion and Carcharhinus; and 6 families of osteichthyans, Sparidae, Acanthuridae, Scaridae, Labridae, Sphyraenidae and Tetraodontidae. This fish assemblage points out to infra-littoral-neritic, tropical warming waters environments with normal salinity.

Keywords: Rio Banano Formation, Lower Miocene, Heptranchias, Mitsukurina, Carcharhinidae, Scaridae, Costa Rica.

RESUMEN: Se estudia la ictiofauna de la localidad de Pacuare de Tres Equis de edad Mioceno Inferior donde se registran 8 géneros de tiburones: Heptranchias, Megaselachus, Isurus, Carcharias, Mitsukurina, Hemipristis, Negaprion y Carcharhinus; y 6 familias de osteíctios, Sparidae, Acanthuridae, Scaridae, Labridae, Sphyraenidae y Tetraodontidae. Esta asociación de peces sugiere un ambiente marino sublitoral - nerítico, con aguas cálidas tropicales y salinidad normal.

Palabras clave: Formación Río Banano, Mioceno Inferior, Heptranchias, Mitsukurina, Carcharhinidae, Scaridae, Costa Rica.
\end{abstract}




\section{INTRODUCCIÓN}

La paleoictiofauna de la Formación Río Banano ha sido registrada por diversos autores; Aguilera \& Rodrigues de Aguilera (1999), estudiaron las secciones del Mioceno Superior Plioceno Inferior de las localidades de Quitaría y La Bomba, describiendo 19 géneros de peces óseos; Laurito et al. (2008), describieron 4 géneros de tiburones y 2 géneros de osteíctios del Mioceno Medio (sensu Laurito et al., 2011) procedentes de la localidad de Lomas de Siquirres, todos de la provincia de Limón. El presente trabajo tiene como objetivo dar a conocer los nuevos registros de peces fósiles de la Formación Río Banano, recuperados en la localidad de Pacuare de Tres Equis, misma que se localiza en las coordenadas $9^{\circ} 55^{\prime} 20.0^{\prime \prime} \mathrm{N} / 83^{\circ} 33^{\prime} 13.3^{\prime \prime} \mathrm{W}$ de la hoja Tucurrique (3445 I) escala 1:50 000 del IGN (Fig.1).

\section{Geología}

El afloramiento donde se recuperó el material es un banco sedimentario de aproximadamente 8 $\mathrm{m}$ de espesor, compuesto de estratos decimétricos hasta métricos de areniscas finas, medias y gruesas, homogéneas, que se alternan con lentes decimétricos de gravas finas ligeramente gradadas, compuestas por intraclastos de areniscas y arcillas de color verde claro con abundante detrito biogénico, los clastos muestran contacto puntual $\mathrm{y}$ algunos pocos alcanzan los $10 \mathrm{~cm}$ de diámetro. Entre los restos biogénicos que se observan en estos lentes de granulometrías gruesas abundan las espinas de equinodermos, son infrecuentes los restos de moluscos y se recuperaron algunos fragmentos retrabajados de coral; dientes de tiburones y peces óseos, estos ictiolitos son relativamente escasos, no se han encontrado dientes de rayas ni otolitos de peces óseos.

\section{PALEONTOLOGÍA}

Clase Chondrichthyes Huxley, 1880

Subclase Elasmobranchii Bonaparte, 1838

Corte Euselachii Hay, 1922

Subcohorte Neoselachii Compagno, 1977

Superorden Squalomorphii Compagno, 1973

Orden Hexanchiforme Buen, 1926

Suborden Hexanchoidei Garman, 1913

Familia Hexanchidae Gray, 1851

Género Heptranchias Rafinesque, 1810

Heptranchias perlo (Bonaterre, 1788)

Mioceno - Reciente

Material: 1 diente.

Descripción: el CFM-5095 (fig. 5: 1a-b) corresponde al primer diente superior anterior con corona alta, muy esbelta y sigmoide, presenta filos laterales lisos en su mitad superior. Su raíz está rota, pero es muy baja en comparación con la corona, además presenta un canal nutricio angosto en la cara basal que es plana.

Discusión: los dientes superiores anteriores del género Heptranchias son muy característicos y fácilmente diferenciable de cualquier otro género de Hexanchiforme (ver Laurito, 1999, p. 32). Por otro lado, el diente descrito no se diferencia de la especie actual Heptranchias perlo (Bonaterre, 1788).

Distribución paleogeográfica: Heptranchias perlo ha sido descrito para el Mioceno Medio de Parma en Italia (Cigala Fulgosi, 1977), Mioceno de la India (Sahni \& Mehrotra, 1981) y Australia (Kemp, 1991). Heptranchias sp. se registra en el Mioceno Medio de Baja California en México (González-Rodríguez et al., 2013). En la región del Caribe, $H$. perlo se ha descrito para el Mioceno Superior- Plioceno Inferior de la Formación Cubagua de Venezuela (Aguilera \& Rodrigues de Aguilera, 2001; Aguilera, 2010; Aguilera \& Lundberg, 2010; Aguilera et al., 2011) y Mioceno Superior - Plioceno Inferior de 


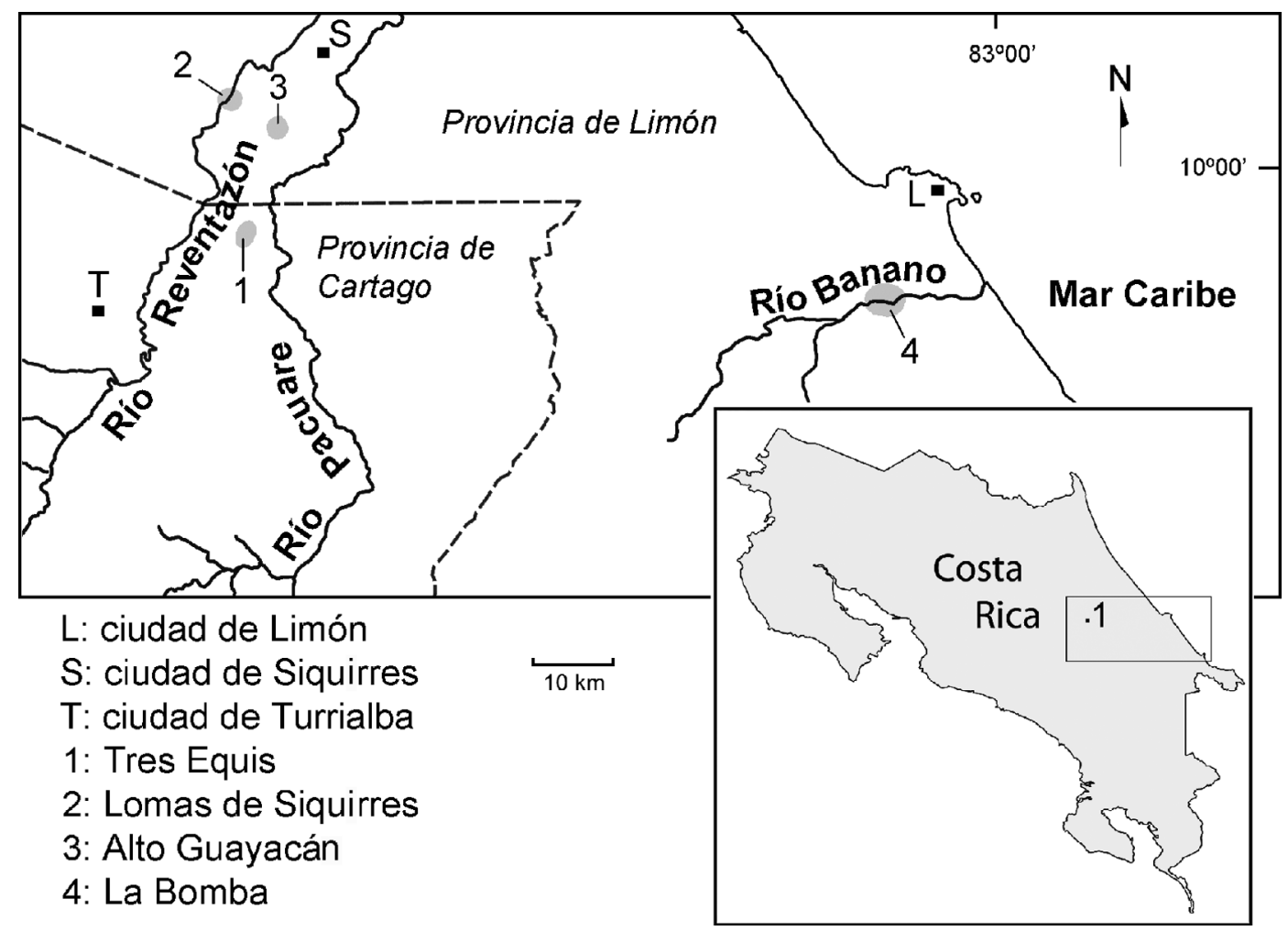

Fig. 1: Mapa de ubicación de las localidades miocénicas del Caribe portadoras de peces fósiles y área de estudio.

la Formación Uscari (Laurito, 1999). El presente registro, correspondiente al Mioceno Inferior de la Formación Río Banano, constituye el segundo registro fósil de esta especie para Costa Rica.

Paleoecología: H. perlo (Bonaterre, 1788) de acuerdo a Compagno (1984a) es un tiburón bentónico de aguas profundas, común sobre las plataformas continentales e insulares y el talud continental superior, con rango de profundidad variable entre los 27 y $720 \mathrm{~m}$. Se alimenta de peces óseos y calamares.

Orden Lamniformes Berg, 1958

Familia Otodontidea Glückman, 1964

Género Megaselachus Glückman, 1964
Megaselachus subauriculatus (Agassiz, 1838)

Mioceno Inferior-Plioceno Inferior

Sinonimia: Otodus (Megaselachus) chubutensis [Ameghino 1901 a 1902] en Cappetta (2012, p. 227).

Material: 2 dientes.

Descripción: dientes de gran tamaño de los cuales solo se preservó la corona que es triangular y alta. El CFM-5093 (fig. 4:1a-c) corresponde a un diente superior probablemente de posición lateral que se caracteriza por una corona ligeramente angosta, fuertemente aserrada y una altura aproximada de 48 $\mathrm{mm}$; su cara labial es convexa y presenta un conspicuo cuello triangular; su cara lingual es cóncava. 
El CFM-5094 (Fig. 4: 2a-c) corresponde a un diente inferior de posición anterior que se caracteriza por presentar una corona fuertemente aserrada, relativamente angosta y una altura aproximada de $50 \mathrm{~mm}$; su mitad inferior es notablemente más ancha. Su cara lingual es notablemente cóncava y su cara labial es ligeramente convexa.

Discusión: las características que presentan los dientes acá recuperados son similares a los descritos por Aguilera et al. (2008) y que Aguilera (2010) considera son suficientes para hacer una diferenciación confiable de la especie Megaselachus megalodon (Agassiz, 1843). En nuestro caso, las características más notables son el relativo pequeño tamaño de la especie Megaselachus subauriculatus (Agassiz, 1838) en comparación con los dientes de Megaselachus megalodon (Agassiz, 1843); además de la fuerte convexidad de la cara labial.

Distribución paleogeográfica: la especie $M$. subauriculatus (Agassiz, 1838) ha sido descrita en el Mioceno Inferior de Cuba (Iturralde-Vinent et al., 1996) y Venezuela en las Formaciones Castillo y Cantaure; Mioceno Superior- Plioceno Inferior de las Formaciones Cubagua y Paraguaná, también en Venezuela (Aguilera, 2010; Aguilera \& Lundberg, 2010).

El presente hallazgo, constituye el primer registro de la especie M. subauriculatus (Agassiz, 1838), para Costa Rica y el segundo para América Central ya que ha sido recientemente registrado en el Mioceno Inferior de Panamá, en la Formación Culebra por Pimiento et al., (2013a) como Carcharocles chubutensis Ameghino, 1906.

Familia Lamnidae Müller \& Henle, 1836

Género Isurus Rafinesque, 1810

\section{Isurus oxyrinchus Rafinesque, 1810}

Sinonimia: para un detallado análisis de la sinonimia de la especie Isurus oxyrinchus Rafinesque, 1810, ver Marsili et al. (2007). De acuerdo a Purdy et al. (2001), consideran la especie Oxyrhina desori es un sinónimo junior de la especie Isurus oxyrinchus Rafinesque, 1810.
Material: 3 dientes.

Descripción: los CFM-5086 (Fig. 2: 4) y CFM-5087 (Fig. 2: 5) corresponden a coronas de dientes anteriores superiores de $19 \mathrm{~mm}$ y $24 \mathrm{~mm}$ de altura, respectivamente; triangulares, altas, suavemente sigmoides y ligeramente volcadas hacia la comisura; con filos suaves que se extienden desde el ápice hasta la base; la cara labial es casi plana, ligeramente convexa e inflada y presenta un repliegue basal, en tanto la cara lingual es semicilíndrica.

El diente CFM- 5090 (Fig. 2: 6) corresponde a un diente inferior lateral con la raíz fragmentada de aproximadamente $15 \mathrm{~mm}$ de altura, por su altura, probablemente corresponde a un individuo juvenil. Además, es levemente inflada, sigmoide y presenta una corona triangular con filos lisos, ligeramente volcada hacia la comisura; su cara labial es bastante plana con un pliegue basal que se eleva hasta su sección media, en tanto su cara lingual es fuertemente convexa.

Discusión: a pesar de que solo se recuperaron dientes fragmentados, las coronas de los dientes superiores no se diferencian de las coronas de los dientes anteriores de la especie actual Isurus oxyrinchus Rafinesque, 1810. Lo mismo sucede con el diente inferior lateral cuya morfología es característica de esta especie.

Distribución paleogeográfica: Isurus oxyrinchus Rafinesque, 1810 se distribuye ampliamente en el Neógeno de Europa (Zbyszewsi \& Moitinho D'Almeida, 1950; Serralheiro, 1954; Menesini, 1969; Cappetta, 1970; Landini, 1977; Antunes et al., 1981; Cappetta \& Nolf, 1991; Ward \& Bonavia, 2001; Antunes \& Balbino, 2003; Marsili, 2007; Marsili et al, 2007). Fuera de Europa en el Mioceno Inferior de Australia (Fitzgerald, 2004); Plioceno de África (Antunes, 1978); Mioceno (Yabe \& Hirayama, 1998; Kuga, 1985) y Pleistoceno (Uyeno \& Matsushima, 1974) de Japón.

En América del Norte se registra en el Mioceno Inferior de la Formación Trent (Case, 1980) y Plioceno de Carolina del Norte (Purdy et al., 2001); Mio-Plioceno y Pleistoceno de California (Boessenecker, 2011; Long, 1993) y Mio-Plioceno de la península de Baja California 
(Espinosa-Arrubarena \& Applegate, 1981; Ashby, 1987; González-Barba, 1996; GonzálezRodríguez et al., 2013) y en América del Sur en el Plioceno de Perú (de Muizon \& DeVries, 1985) y Mioceno de Chile (Suarez et al., 2006).

A pesar de que en la actualidad la especie se encuentra presente en el Caribe (Compagno, $1984 b$ ), su registro fósil en esta región no es tan abundante. De acuerdo a Aguilera (2010) Isurus cf. oxyrinchus inicialmente descrito por Leriche (1938) como Oxyrhina cf. desori (Agassiz, 1843) se registra en el Miembro Menecito de la Formación San Lorenzo del Oligo-Mioceno de Venezuela y Portell et al. (2008) la registran en la Formación Grand Bay del Mioceno Medio de la isla de Granada.

En América Central se registró la especie Isurus oxyrincus Rafinesque, 1810, en el Mioceno Superior-Plioceno Inferior de la Formación Uscari, en Costa Rica, ésta fue descrita inicialmente por Laurito (1999) como Isurus retroflexus (Agassiz, 1843). El presente hallazgo de la Formación Río Banano corresponde al segundo registro de la especie Isurus oxyrincus Rafinesque, 1810 para Costa Rica.

Paleoecología: Isurus oxyrincus Rafinesque, 1810 , es un tiburón de mar abierto, pantropical y pelágico que alcanza los $500 \mathrm{~m}$ de profundidad, aunque suele visitar la zona litoral y aguas con temperaturas cercanas a los $16^{\circ} \mathrm{C}$. Su dieta consiste de una gran variedad de peces óseos demersales y pelágicos, así como de tiburones y rayas (Compagno, 1984a)

Familia Odontaspididae Müller \& Henle 1839 Género Carcharias Rafinesque, 1810

Sinónimos del género actualmente utilizados: Odontaspis Agassiz, 1838; Eugomphodus Gill, 1862 y Synodontaspis White, 1931.

\section{Carcharias acutissima (Agassiz, 1843)}

Sinonimia: para un detallado análisis de la sinonimia de la especie Carcharias acutissima (Agassiz, 1843), ver Marsili et al. (2007).

Material: 1 diente.
Descripción: el CFM-5091 (Fig. 3: 1a-c) corresponde a un diente anterior inferior del que solo se recuperó la corona que se caracteriza por ser muy alta $(28,28 \mathrm{~mm})$, esbelta, volcada lingualmente de manera suave y sigmoide, con la cara labial ligeramente convexa casi plana y la cara lingual notablemente convexa. Además, se observan dos filos lisos prominentes que se extienden desde el ápice hasta prácticamente la base, donde terminan formando una especie de cintura donde la base de la corona se ensancha, no se preservaron las cúspides accesorias.

Discusión: a pesar de que el diente está incompleto, el gran tamaño relativo de la corona, una base lingual redonda y ensanchada, más el tener un base labial relativamente recta y lisa, permite distinguirle de otras especies neógenas, como por ejemplo de los dientes inferiores anteriores de Hemipristis serra ya que los filos de la corona en esta última especie solo abarcan el primer tercio superior.

Distribución paleogeográfica: Carcharias acutissima (Agassiz, 1843), aparece en el Oligoceno Superior de Alemania (Reinecke et al., 2001), Mioceno-Plioceno de Europa (p.e. Leriche, 1910; Schultz, 1969; Vaello i Aparicio, 1989; Cappetta, 1987; Nolf, 1988; García et al., 2009) y es una especie que prácticamente se registra en todas las localidades de edad Mio-Plioceno portadoras de tiburones del mundo (Cappetta, 1987); p.e. en el Mioceno de Japón (Itoigawa \& Nishimoto, 1974), Plioceno de Australia (Pledge, 1985) y Pleistoceno de Sudáfrica (Kensley, 1985).

En América del Norte, esta especie ha sido registrada en el Oligoceno Medio de la Formación el Cien en la Península de Baja California, México (González-Rodríguez et al., 2013). La Formación Saint Marys del Mioceno de Maryland (Leriche, 1942); la Formación Pungo River del Plioceno Inferior de North Carolina (Purdy et al., 2001) y en la localidad de Arroyo Salada del Plioceno de Baja California Sur en México (Ashby, 1987). En América del Sur, en el Mioceno Superior de Uruguay (Perea \& Ubilla, 1989) y Argentina (Cione et al., 2000, 2013). 

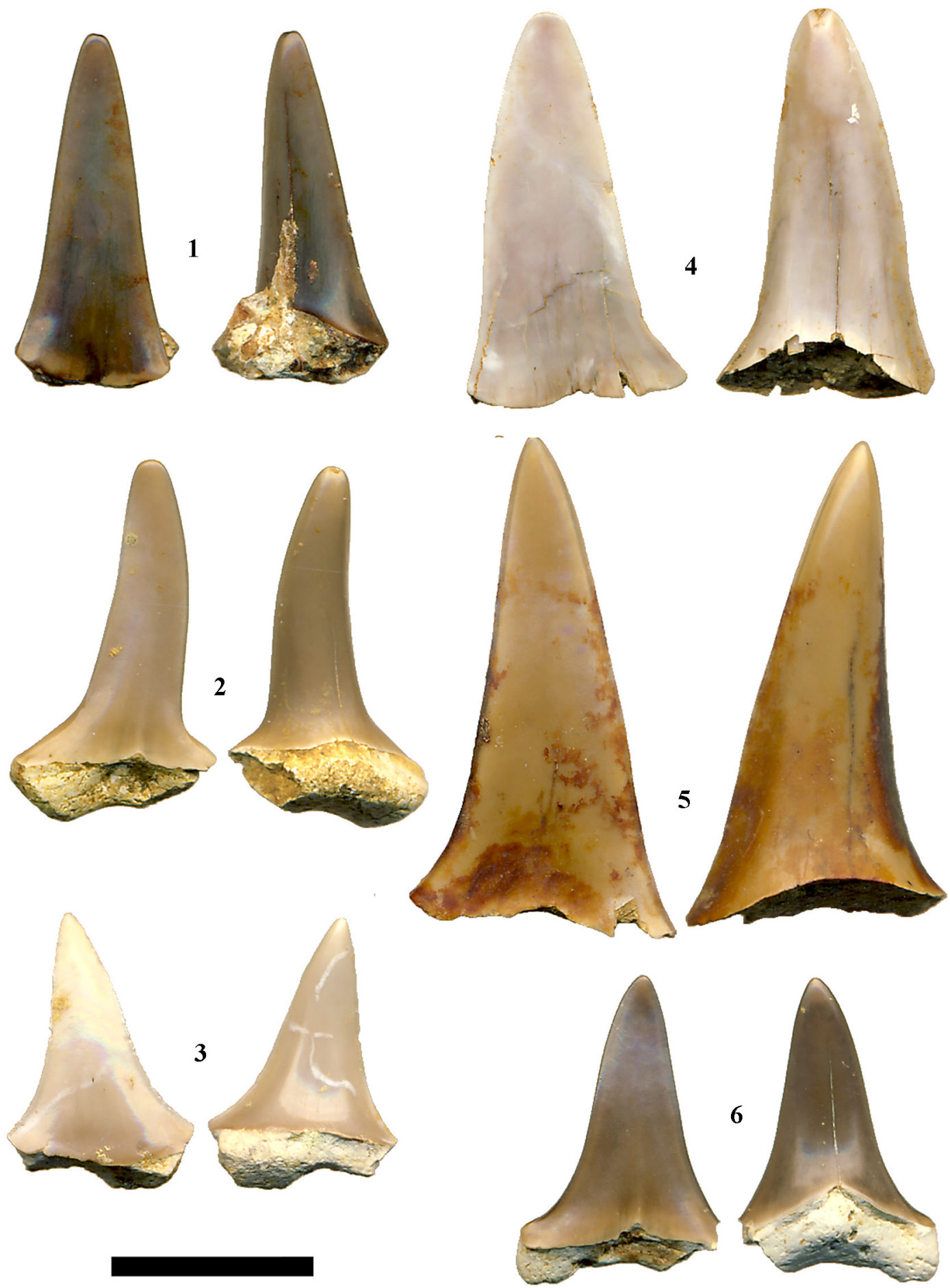

Fig. 2: Negaprion eurybathrodon (Blake, 1862), 1. diente inferior y 2. diente superior; Carcharhinus sp., 3.diente inferior; Isurus oxyrinchus Rafinesque, 1810, 4. y 5. dientes superiores anteriores y 6 diente inferior lateral. Vistas: izquierda labial y derecha lingual. Escala visual $1 \mathrm{~cm}$. 

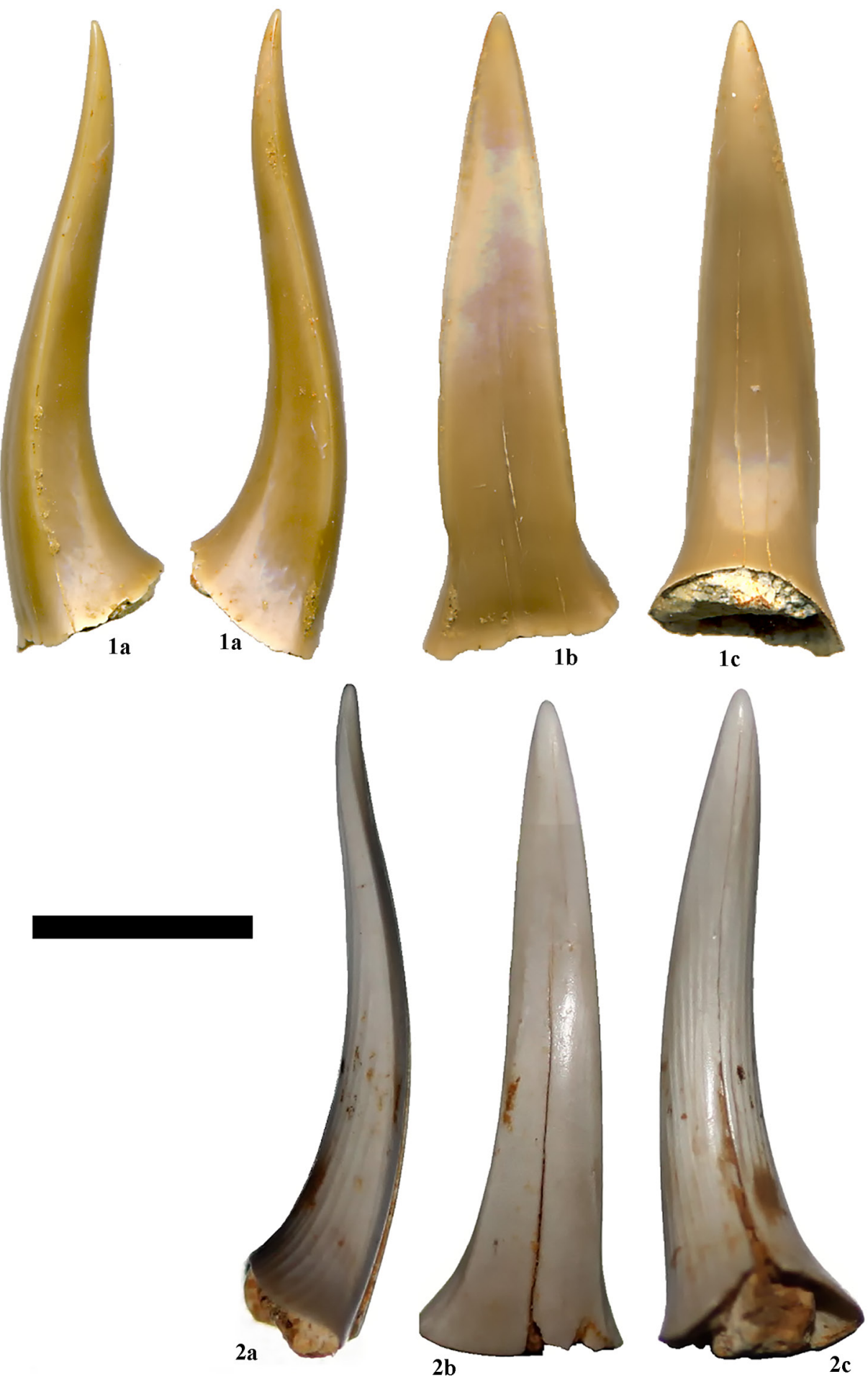

Fig. 3: 1. Carcharias acutissima (Agassiz, 1843), diente anterior inferior; escala $1 \mathrm{~cm} ; 2$. Mitsukurina sp., diente anterior, en vistas a. lateral, b. labial y c. Lingual, escala $0.5 \mathrm{~cm}$. 
En el Caribe la especie actual Carcharias taurus Rafinesque, 1810; que algunos autores (p.e. Arambourg, 1927) consideran está muy cercanamente relacionada con la especie fósil Carcharias acutissima (Agassiz, 1843), ha sido registrada en el Mioceno Medio de Cuba (Leriche, 1938; Iturralde-Vinent et al., 1996); el Mioceno Medio de la Formación Grand Bay de la isla de Granada (Portell et al., 2008) y el Mioceno SuperiorPlioceno Inferior de la Formación Cubagua en Venezuela (Aguilera, 2010; Aguilera et al., 2011); existe la posibilidad de que estas dos especies sean sinónimos pero al igual que Marsili et al. (2007); preferimos mantener la nomenclatura del taxón fósil, hasta que no se realice un detallado estudio comparativo que clarifique su estatus taxonómico.

El presente hallazgo, constituye el segundo registro de la especie Carcharias acutissima (Agassiz, 1843), para Costa Rica y América Central ya que Kruckow (1975) y Kruckow \& Thies (1990), registran Eugomphodus acutissimus para el Mioceno Medio del Río Reventazón en Turrialba, pero no está claro su procedencia estratigráfica exacta, podría tratarse de la Formación Río Banano.

Cione et al. (2007) sugieren la hipótesis que durante el Plioceno Medio la drástica caída del nivel del mar redujo notablemente la extensión de las plataformas continentales e insulares y junto con la caída general de la temperatura, este género se vio obligado a migrar a latitudes más cálidas, provocando así la desaparición de la especie del Pacífico suramericano. Ellos consideran que este género no volvió a recolonizar esta zona del Pacífico, pues el cierre de Istmo de Panamá hace alrededor de $3 \mathrm{Ma}$ constituyó una barrera oceánica efectiva para los individuos del Caribe y del Atlántico.

Paleoecología: probablemente fue un tiburón que habitó tanto las plataformas continentales como insulares; teniendo en cuenta su amplia paleogeografía puede deducirse que al igual que en la especie actual Carcharodon carcharias (Linnaeus, 1758), se distribuyó tanto en mares tropicales como subtropicales de todo el planeta, principalmente en ambientes nectónicos y menos común en el epipelágico, sobre todo del Mioceno y el Plioceno Inferior.

Su dieta no debió de ser diferente de la observada en la especie actual que consiste de peces óseos y pequeños tiburones y rayas, así como de calamares, cangrejos y langostas (sensu Compagno, 1984a).

Familia Mitsukurinidae Jordan, 1898

Género Mitsukurina Jordan, 1898

\section{Mitsukurina sp.}

Material: 1 diente

Descripción: el CFM-5092 (fig. 3: 2a-c), corresponde a un diente anterior de posición incierta del cual solo se preservó la corona de pequeño tamaño, de $13.64 \mathrm{~mm}$, esbelta, sigmoide y ligeramente volcada a la comisura; su cara labial es suavemente convexa y su cara lingual fuertemente convexa y finamente estriada; presenta filos suaves que se extienden desde la cúspide hasta la base de la corona.

Discusión: diente lamniforme que recuerda a los dientes del género actual Carcharias y los géneros Scapanorhynchus Woodward, 1889 del Cretácico y Striatolamia Glükman, 1964 del Paleoceno; pero debido a sus relativamente pequeñas dimensiones, esbeltez, la particular presencia de finas estriaciones en su cara lingual y filos que se prolongan hasta la base de la corona, son características propias del género actual Mitsukurina, ello es acorde con los criterios dados y utilizados por David P. Ward en BienkowskaWasiluk \& Radwanski (2009) para la determinación del ejemplar polaco.

Por otra parte, el espécimen recuperado es indiferenciable de la especie miocénica Mitsukurina linneata (Probst, 1879).

Distribución paleogeográfica: el género Mitsukurina Jordan, 1898 se registra en el Eoceno de Australia (Pledge, 1967) y Europa, en el Ypresiano de Dinamarca (sensu Ward en 
Cappetta, 2012) y Francia (sensu Adnet, 2006); en el Oligoceno Inferior de los Cárpatos polacos (Bienkowska-Wasiluk \& Radwanski, 2009). Mioceno de Japón en la Formación Niwaya (Takakuwa, 2006); Plioceno de Italia (CigalaFulgosi, 1986) y Angola (Antunes, 1978). En el continente americano se registra en el Oligoceno Superior de California (Phillips et al., 1976).

La especie Mitsukurina linneata (Probst, 1879) ha sido descrita en el Mioceno Inferior de Baltringen, Alemania (Probst, 1879); Mioceno del valle del Rhône en Francia, Suiza y Austria (Cappetta, 1987; Leriche, 1927; Schultz, 1968; Bolliger et al., 1995; Vialle et al., 2011).

La especie actual Mitsukurina owstoni Jordan, 1898 como fósil ha sido registrada en el Pleistoceno tardío de Madagascar (Roux \& Geistodoerfer, 1988) y de manera reciente ha sido registrado en la bahía de Nenguange en el Parque Natural Tayrona en el Caribe de Colombia (Grijalba-Bendeck \& Acevedo, 2009). El primer registro actual de Mitsukurina owstoni Jordan, 1898 para América, se dio en la Guyana Francesa en el Atlántico occidental y fue dado a conocer por Last \& Stevens (1994); seguido por los hallazgos de 1998 en el Pacífico al sur de California (Ugoretz \& Siegel, 1999) y del 2000 en el Golfo de México (Parsons et al., 2002). Fuera del continente americano, sus hallazgos escasos y puntuales se registran en el Atlántico oriental en la Bahía de Vizcaya, en las islas Madeira, Senegal, Golfo de Guinea y Sudáfrica, en el océano Indico occidental, el este de Sudáfrica, Mozambique y en el Pacífico occidental, en Japón, Australia y Nueva Zelandia (Compagno, 2002).

Paleoecología: fundamentados en la especie actual, se sabe que habita las plataformas externas y los taludes continentales entre los $270 \mathrm{y}$ $960 \mathrm{~m}$, donde se dan la mayoría de los registros, pero pueden alcanzar los $1300 \mathrm{~m}$ de profundidad y algunas veces se les ha registrado en el nerítico entre los 95 y $137 \mathrm{~m}$. Su registro en los montes marinos, sugiere que esta especie es oceánica o semioceánica (Compagno, 2002).
Los dientes delgados y pequeños sugieren que estos tiburones se alimentan de presas de cuerpos suaves que incluyen peces óseos, camarones y calamares (Compagno, 2002).

Orden Carcharhiniformes Compagno, 1973

Familia Hemigaleidae Agassiz, 1843

Género Hemipristis Agassiz, 1843

\section{Hemipristis serra Agassiz, 1835}

Sinonimia: para un detallado análisis de la sinonimia de la especie Hemipristis serra Agassiz, 1835, ver Antunes \& Jonet (1970), Cappetta (1970), Laurito (2004) y Marsili et al. (2007).

Material: 2 dientes

Descripción: el CFM-5107 (fig. 5: 2a-b), corresponde a un diente superior, anterior, del cual solo se preservó la corona, ésta es de pequeño tamaño, $12.58 \mathrm{~mm}$, volcada en sentido comisural; sus caras labial y lingual son convexas; además, presenta un filo comisural fuertemente aserrado, en tanto que el filo mesial es finamente aserrado. El CFM-5179 corresponde a un diente superior y anterior, muy similar al anterior, del que sólo se preservó la corona de $1 \mathrm{~cm}$ de alto, se trata probablemente de ejemplares inmaduros.

Discusión: los dientes recuperados, a pesar de estar fragmentados, son fáciles de reconocer debido a su morfología característica y a las diferencias en el tipo de aserramiento observables entre los filos mesial y comisural.

Distribución paleobiogeográfica: en América Central la especie Hemipristis serra Agassiz, 1835, fue descrita para el Mioceno Medio (Gillette, 1984) y Mioceno Tardío (Pimiento et al., 2013b) de la Formación Gatún y más recientemente en la Formación Culebra en el Mioceno temprano (Pimiento et al., 2013a), ambas en Panamá. En Costa Rica, la especie Hemipristis serra Agassiz, 1835, se ha registrado para la Formación Punta Judas, dicha determinación fue hecha por el Dr. Kruckow (en Seyfried et al., 1985) y en la Formación Punta 

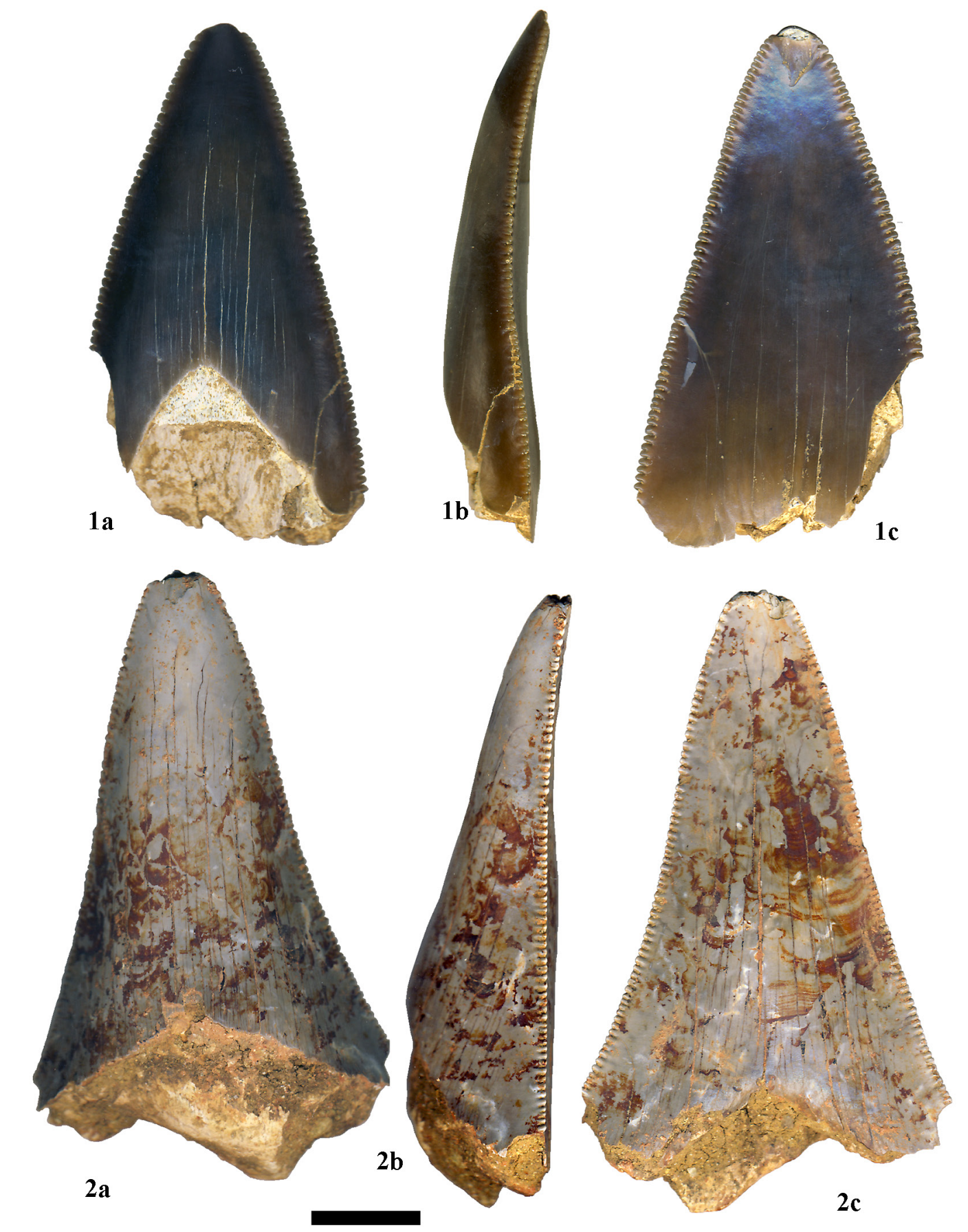

ig. 4: Megaselachus subauriculatus (Agassiz, 1838), dientes laterales, 1. superior y 2. Inferior en vistas a. lingual, b. lateral y c. labial. Escala visual $1 \mathrm{~cm}$. 

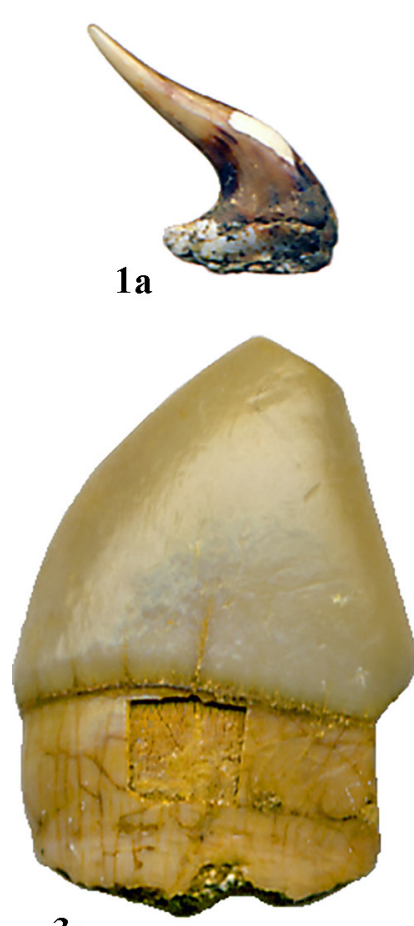

3a

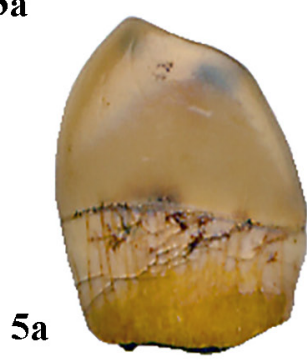

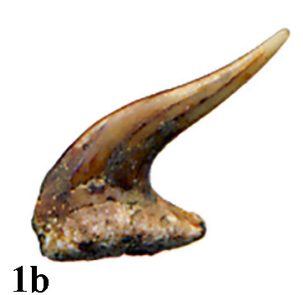

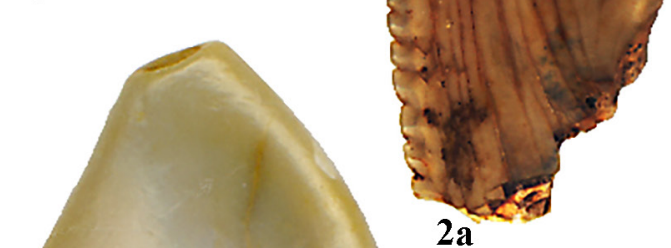

\section{$3 \mathrm{~b}$}

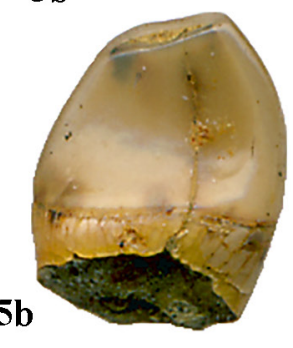

$2 a$

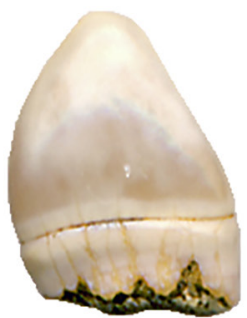

$4 a$
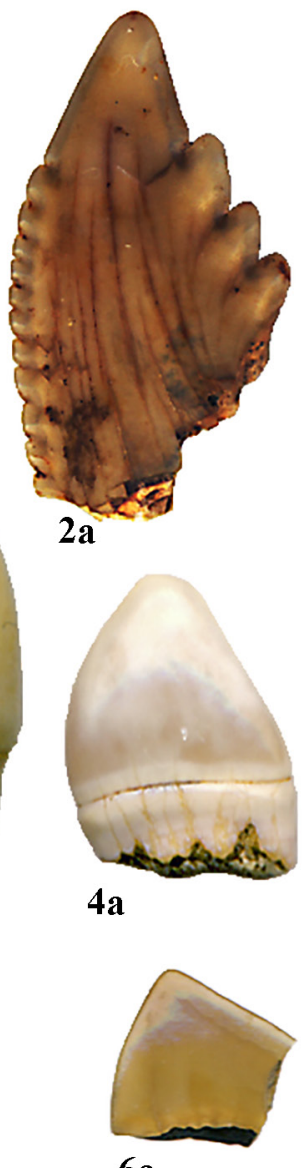

6a
$2 \mathrm{~b}$

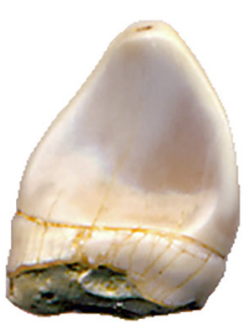

$4 b$

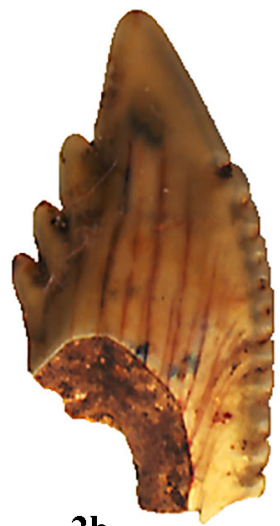

$\mathbf{2 b}$

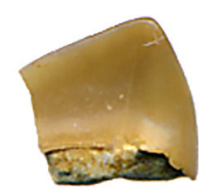

6b

Fig. 5: 1. Heptranchias perlo, primer diente anterior superior en vista a. anterolateral y b. anteroposterior; 2. Hemipristis serra Agassiz, 1835, diente lateral superior; 3-6. Diplodus jomnitanus Valenciennes, 1844, 3-5 dientes laterales y 6. diente incisiviforme. En vistas a. labial y b. lingual, escala visual: $1 \mathrm{~cm}$, excepto para $2 \mathrm{a}$ y b que equivale a $0,5 \mathrm{~cm}$.

Carballo (Kruckow \& Thies, 1990); ambas del Mioceno Medio y aflorantes en la costa pacífica central; en las localidades de Lomas de Siquirres de edad Mioceno Medio y perteneciente a la Formación Río Banano (Laurito et al., 2008, 2011) y de Alto Guayacán, Mioceno SuperiorPlioceno Inferior de la Formación Uscari, ambas aflorantes en la región Caribe (Laurito, 1999). Recientemente se registró en la localidad de San
Gerardo de Limoncito del Mioceno Superior de la Formación Curré en el sur del país (Laurito \& Valerio, 2008).

En general Hemipristis serra Agassiz, 1835 debe ser considerada una especie cosmopolita y pantropical, ya que su registro es muy común en todos los afloramientos neríticos portadores de tiburones tropicales o subtropicales del Mioceno y Plioceno del planeta. 
Paleoecología: la especie actual Hemipristis elongatus (Klunzinger, 1871) es un tiburón costero y nectónico en las aguas someras de las plataformas insulares y continentales del océano Indico y Pacífico Occidental en aguas con profundidades de 1 a $3 \mathrm{~m}$. Se alimenta de peces óseos, tiburones y rayas (sensu Compagno, 1984b). Fundamentado en ello la especie fósil Hemipristis serra Agassiz, 1835 debe ser considerado un tiburón de hábitos nectónicos y epipelágico, habitante de las plataformas continentales e insulares de los mares cálidos y con una distribución pantropical durante el Cenozoico Superior (Laurito \& Valerio, 2008). Teniendo en cuenta lo anterior y su amplia distribución paleobiogeográfica, se puede deducir que Hemipristis serra Agassiz, 1835 probablemente habitó aguas con rango de profundidad mayor que la especie actual, al menos entre los $1 \mathrm{~m}$ a poco más de 100 $\mathrm{m}$.

Familia Carcharhinidae Jordan \& Evermann, 1896 Género Negaprion Whitley, 1940

Negaprion eurybathrodon (Blake, 1862)

Mioceno Inferior - Mioceno Superior (Laurito, 2004)

Sinonimia: para un detallado análisis de la sinonimia de la especie Negaprion eurybathrodon (Blake, 1862), ver Antunes \& Jonet (1970) y Laurito (2004). Pimiento et al. (2013b) consideran que la especie actual Negaprion brevirostris (Poey, 1868) y la especie fósil Negaprion eurybathrodon (Blake, 1862) son sinónimos.

Material: 2 dientes.

Descripción: el CFM-5085 (Fig. 2: 1) corresponde a diente inferior lateral caracterizado por una corona recta y cúspide con ápice redondeado, con la cara labial suavemente convexa y la cara lingual fuertemente convexa, filos tersos y un pequeño repliegue basal; y una altura aproximada de 17,64 mm. El CFM-5088 (Fig. 2: 2) corresponde a un diente superior lateral con una altura aproximada de $18 \mathrm{~mm}$, caracterizado por una cúspide alta y esbelta, curvada comisuralmente con filos tersos, el comisural es recto y el mesial es con- vexo, se observa un fragmento de la raíz.

Discusión: aunque solamente se cuenta con coronas prácticamente aisladas, sus características se ajustan a las descritas para la especie Negaprion eurybathrodon (Blake, 1862) por White (1955); Jonet et al. (1975); Longbottom (1979).

Distribución paleogeográfica: la especie Negaprion eurybathrodon (Blake, 1862) fue inicialmente descrita como Lamna eurybathrodon por Blake, 1862 en el Mioceno Medio de la Formación Gatún en el extremo norte del Canal de Panamá (sensu White, 1955) y recientemente se ha descrito la especie actual Negaprion brevirostris (Poey, 1868) como fósil para el Mioceno temprano de la Formación Culebra y Mioceno Superior de la Formación Gatún (Pimiento et al., 2013b), fuera de Panamá en América Central, la especie ha sido descrita la Formación Punta Judas de edad Mioceno Medio (Laurito, 2004) y el presente registro correspondiente a la Formación Río Banano.

En el Caribe la especie Negaprion eurybathrodon (Blake, 1862) ha sido descrita en el Mioceno de la isla de Trinidad en la Formación Tamana (Casier, 1958); Mioceno Inferior de la Formación Cantaure (Aguilera \& Rodrigues de Aguilera, 2001); Mioceno Superior de las Formaciones Caujarao, Urumaco y Codore y Mioceno Superior-Plioceno Inferior de la Formación Paraguaná, todas en el Caribe de Venezuela (Aguilera, 2010; Sánchez-Villagra \& Aguilera, 2006).

En América del Sur la especie Negaprion eurybathrodon (Blake, 1862), se ha registrado en las localidades de Punta Colorada, Punta Gorda y Punta Bellaca de la Formación Borbón del Mioceno Tardío (Longbottom, 1979) y como Negaprion brevirostris en la localidad de Flavio Alfaro de la Formación Angostura y de edad Mioceno Medio-Tardío (Carrillo-Briceño et al., 2014), ambas del Ecuador. En el Mioceno Superior de Piura en Perú como Negaprion sp. aff. N. brevirostris (sensu Apolín et al., 2007). En América del Norte se ha registrado en el Mioceno Medio de South Carolina (Gibbes, 1848; Leriche, 1942); Mioceno Medio de North Carolina en la Formación Belgrade (Müller, 1992), Mioceno 
Inferior de Maryland (Eastman, 1904; Kruckow $\&$ Thies, 1990), Mioceno Medio de Florida en la Formación Hawthorn (White, 1955) y el Plioceno de Baja California en México como Negaprion brevirostris (González-Rodríguez et al., 2013).

En Europa, la especie Negaprion eurybathrodon (Blake, 1862) ha sido descrita en el Mioceno Inferior del centro de Italia (Marsili et al., 2007); Mioceno Medio de Loupian en el sur de Francia (Cappetta, 1970, 1987) y de Portugal (Zbyszewski \& D'Almeida, 1950; Serralheiro, 1954; Antunes \& Jonet, 1970; Jonet et al., 1975; Antunes et al., 1981).

Esta especie fue descrita por White (1955) para el Mioceno de Weti Creek, Zanzíbar en África y el Mioceno Superior de Melbourne, Australia; recientemente ha sido descrita para el Mioceno Inferior y Medio de la India (Sahni \& Mehrotra, 1981; Ralte et al., 2011).

De manera errónea, Case \& West (1991) describieron esta especie para el Eoceno tardío de la Formación Kirthar en el Miembro Drazinda en Pakistán que de acuerdo a Adnet et al. (2007), corresponde a la especie indeterminada Negaprion sp. para el Oligoceno temprano de Beluchistán.

Paleoecología: los tiburones del género Negaprion habitan en la actualidad los fondos de las áreas costeras y sublitorales de las plataformas continentales e insulares de los mares tropicales hasta al menos los $90 \mathrm{~m}$ de profundidad. Frecuentan los manglares, desembocaduras de ríos y los arrecifes de coral y salen a mar abierto con fines migratorios; se alimentan principalmente de peces óseos, crustáceos y moluscos, pero también se alimentan de rayas y eventualmente de aves marinas (sensu Compagno, 1984b).

Género Carcharhinus Blainville, 1816

Carcharhinus sp. indet.

Material: 1 diente.

Descripción: el CFM-5089 (Fig. 2: 3) corresponde a una corona de un diente inferior lateral de $13 \mathrm{~mm}$ de alto; ligeramente volcada hacia la comisura y hacia atrás con filos con aserramiento apenas perceptible. La cara labial es ligeramente convexa y la cara lingual fuertemente convexa.
No se observa repliegue basal.

Discusión: la corona es característica de un diente inferior de Carcharhinus spp., pero por ser tan escaso y fragmentario el material no es posible asociarlo a ninguna especie en particular.

Distribución paleobiogeográfica: el género Carcharhinus está presente en la Formación Punta Judas y en la localidad de Lomas de Siquirres de la Formación Río Banano, ambas del Mioceno Medio; Formación Curré en la sección de San Gerardo de Limoncito de edad Mioceno Superior; Formación Uscari en la localidad de Alto Guayacán de edad Mioceno Superior Plioceno Inferior (Laurito, 1999, 2004; Laurito \& Valerio, 2008, Laurito et al., 2008).

Paleoecología: como cualquier tiburón del género Carcharhinus, habitó las aguas cálidas y templado cálidas de las plataformas continentales e insulares y los ambientes tropicales costeros y pelágicos, tanto en aguas someras muy próximas a la costa y del mar abierto, como en áreas próximas al borde de las plataformas.

Clase ACTINOPTERYGII Klein, 1885

Subclase NEOPTERYGII

Infraclase TELEOSTEI

Magnorden EUTELEOSTEI

Superorden ACANTHOPTERYGII

Orden PERCIFORMES Bleeker, 1859

Familia SPARIDAE Bonaparte, 1831

Género Diplodus Rafinesque, 1810

Diplodus jomnitanus Valenciennes, 1844

Material: 4 dientes.

Descripción: los dientes CFM-5096, CFM5097 y CFM-5098 (fig. 5: 3, 4 y 5 respectivamente) corresponden a dientes latero-comisurales de posición incierta que se caracterizan por ser cuasi ojivales, ligeramente inflados y comprimidos en sentido vestíbulo-lingual, con la cara anterior convexa y la interna cóncava; presentan evidencia de desgaste oclusal. El CFM-5106 (fig. 5: 6a-b) corresponde a un diente fragmentado, tipo incisivo, ancho y comprimido con corona cuadrangular ligeramente más 
ancha que la porción radicular que está fragmentada, la cara anterior es convexa y la interna cóncava. La superficie oclusal muestra desgaste diferencial.

Discusión: los dientes hallados son de tamaño relativamente grandes si se les compara con elementos dentales similares, observados en la morfo especie mio-pliocena Diplodus oweni (Sismonda, 1849), ello permite agruparlo dentro del morfotipo miocénico Diplodus jomnitanus Valenciennes, 1844. Este morfotipo es indiferenciable de la especie actual Diplodus sargus (Valenciennes, 1830) que habita el Mediterráneo, Atlántico Oriental y el Índico sudafricano.

Por su parte, las especies Diplodus argenteus (Valenciennes en Cuvier \& Valenciennes, 1830) común en la costa atlántica de América, desde las Carolinas hasta Brasil y norte de Argentina y Diplodus argenteus caudimacula (Poey 1860) que bordea el Caribe desde el sur de Florida hasta las Antillas Menores, presentan el mismo morfotipo dental y tamaño similar, lo que no permite una distinción a nivel específico.

Distribución paleobiogeográfica: la especie Diplodus jomnitanus Valenciennes, 1844 se registra ampliamente en las formaciones marinas del Mioceno de Europa y el Mediterráneo (Zbyszewski \& D’Almeida, 1950; Serralheiro, 1954; Pawlowska, 1960; Bauzá \& Plans, 1973; Jonet, 1975; Antunes et al., 1981; Ginsburg et al., 2000; Gaudant, 2002). Es la primera vez que se registra éste morfotipo en el continente americano. Anteriormente, se registró de manera errónea este género con la especie Diplodus oweni (Sismonda, 1849) en el Mioceno Superior-Plioceno Inferior de la localidad de Alto Guayacán de la Formación Uscari (Laurito, 1999) es probable que se trate de una especie no descrita de Diplodus o de formas juveniles de Diplodus jomnitanus Valenciennes, 1844.

Paleoecología: son peces de aguas claras costeras someras, con un record de profundidad de $27.5 \mathrm{~m}$; raramente hallado en aguas salobres y muestran preferencia por fondos con vegetación baja. Los adultos se alimentan principalmente de invertebrados bénticos tales como briozoos, bivalvos y esponjas; los juveniles limpian ectoparásitos de otros peces y son zooplanctívoros (Carpenter, 2002).
Género Sparus Linnaeus, 1758

\section{Sparus sp. 1}

Material: 4 dientes

Descripción: El ejemplar ilustrado en la fig. 6: 1 es de una colección privada, propiedad de uno de los autores (CCB). Los ejemplares CFM5100 (fig. 6: 2) y CFM-5101(fig. 6: 3), corresponden a dientes de coronas reniformes y contorno cuasi circular hasta sub elíptico; los dientes CFM5102 (fig. 6: 4) corresponde a un diente lateral y el CFM-5099 (fig. 6: 8) corresponde a un diente caniniforme anterior de posición incierta por su corona de forma cilíndrica y ápice cónico.

\section{Sparus sp. 2}

Material: 5 dientes aislados

Descripción: Los ejemplares CFM-5108, CFM-5109, CFM-5110, CFM-5111 y CFM-5112 (fig.7: 15, 16, 17, 18 y 19, respectivamente) son dientes de muy pequeño tamaño con coronas reniformes circulares a ovales. Su pequeño tamaño se puede interpretar como formas juveniles del género, incluso de la especie anterior.

Discusión: Todo el conjunto concuerda con el morfotipo miocénico Sparus cinctus Agassiz (1843), sobre todo porque algunos de los dientes presentan tamaños relativamente grandes. Este morfotipo probablemente corresponde a varias especies con distribución pantropical.

Distribución paleobiogeográfica: esta especie ha sido descrita ampliamente en el Mioceno de Europa y el Mediterráneo (Zbyszewski \& Moitinho D'Almeida, 1950; Serralheiro, 1954; Menesini, 1969; Pawlowska, 1960; Bauzá \& Plans, 1973; Jonet, 1975; Vaello i Aparicio, 1989) e India (Mehrotra, 1984).

En el Caribe, Casier (1958), describió Sparus para el Cenozoico (probablemente Mioceno) de la Isla de Barbados. En Costa Rica el género Sparus ha sido registrado en el Mioceno Medio de la Formación Río Banano (Laurito et al., 2008); Mioceno Superior de la Formación Curré (Laurito \& Valerio, 2008) y Mioceno Superior-Plioceno Inferior de la Formación Uscari (Laurito, 1999). 
Paleoecología: teniendo en cuenta las especies actuales del género se puede extrapolar que Sparus sp. 1 y Sparus sp. 2, habitaron mares eurihalinos y euritermales, comunes tanto en ambientes marinos y salobres costeros como estuarios y lagunas, fondos rocosos y arenosos hasta profundidades de $50 \mathrm{~m}$ (cf. Colloca \& Cerasi, 2012).

Género Pagrus, Peters, 1855

Pagrus pagrus (Linnaeus, 1758)

Material: 3 dientes.

Descripción: CFM-5103, CFM-5104 y CFM5105 (fig. 6: 5, 6 y 7, respectivamente) son dientes caniniformes anteriores de posición incierta, fragmentados que se caracterizan por presentar cúspides cónicas, anchas y bajas con reborde basal grueso; la cara lingual ligeramente cóncava y la labial convexa.

Discusión: las formas tan particulares de las cúspides preservadas, una de ellas con parte de la base de la corona, son característicos e indiferenciables de los dientes superiores anteriores presentes en el pargo común actual. De allí que se les incluya en la especie Pagrus pagrus (Linnaeus, 1758).

Distribución paleobiogeográfica: el género Pagrus aunque no abundante es común hallarlo en los sedimentos Mio-Pliocenos de Europa y el Mediterráneo (Arambourg, 1927; Bauzá, 1948; Menesini, 1969; Bauzá \& Plans, 1973; Jonet, 1975; Antunes et al., 1981; Gregorová, 2009).

En América Central, el género Pagrus únicamente ha sido registrado en el Mioceno Superior- Plioceno Inferior de la Formación Uscari (Laurito, 1999). El presente hallazgo, constituye el segundo registro del género y el primero de la especie Pagrus pagrus (Linnaeus, 1758) para Costa Rica.

Paleoecología: teniendo en cuenta la especie actual se puede extrapolar que la especie Pagrus pagrus (Linnaeus, 1758) como especie fósil habitó los fondos arenosos endurecidos y los fondos rocosos con rangos de profundidad entre los 10 y los $80 \mathrm{~m}$, recientemente se ha reportado ésta especie en profundidades de hasta $250 \mathrm{~m}$ (cf. Carpenter, 2002).
Género Dentex Cuvier, 1817

\section{Dentex fossilis Jonet 1975}

Material: 2 dientes

Descripción y discusión: Los ejemplares CFM-5113 y CFM-5114 (fig. 8: 10 y 11, respectivamente) corresponden a dientes laterales caniniformes, con la corona curva y lados ligeramente planos con hendidura triangular.

Distribución paleobiogeográfica: el género Dentex ha sido registrado en el Mioceno de India (Mehrotra, 1981); Mioceno Medio de Austria (Schultz, 2001; Gregorová, 2009), Mioceno Superior de Italia (Girone at al., 2010), Algeria (Arambourg, 1927) y la especie Dentex fossilis, Jonet 1975 en el Mioceno Medio de Portugal (Jonet, 1975; Antunes et al., 1981). El presente hallazgo, constituye el primer registro del género en el Caribe.

En la actualidad las especies conocidas del género Dentex, habitan el Indo Pacífico, el Pacífico Suroeste, el Pacífico Oriental y el Atlántico Occidental (sensu Froese \& Pauly, 2013).

Paleoecología: teniendo en cuenta los hábitats de las especies actuales del género Dentex, se puede extrapolar que como fósil la especie Dentex fossilis Jonet 1975, era una especie demersal, habitante de las plataformas y taludes continentales e insulares hasta los $400 \mathrm{~m}$, su dieta consistiría principalmente de peces, tunicados y moluscos.

Familia ACANTHURIDAE Bonaparte, 1832 Género Acanthurus Forsskål, 1775

\section{Acanthurus sp.}

Material: 6 coronas biconvexas, correspondientes a individuos juveniles y de posición incierta.

Descripción: Los dientes CFM-5115, CFM5116, CFM-5117, CFM-5118, CFM-5119 y CFM5120 (fig. 9: 1, 2, 3, 4, 5 y 6, respectivamente), de coronas espatuladas asimétricas compuestas por cúspides digitiformes de número variable entre 6 a 8 , con extremos apicales chatos. Las cúspides centrales suelen ser gruesas y rectangulares, mientras que las cúspides laterales son más cortas y ojivales. 
Discusión: dientes espatulados y poli-cuspidados característicos de los peces cirujanos que no se asemeja a ningún otro percomorfo, por ello los dientes recuperados se incluyen dentro de la familia Acanthuridae.

Distribución paleobiogeográfica: el registro más antiguo de la familia Acanthuridae procede de la localidad Tethysiana del Eoceno Medio (Bellwood, 1996) del Monte Bolca, y el género Acanthurus se ha registrado en el Helvetiano Inferior del sureste de Francia y en varias localidades del Burdigaleano y Langhiniano de Portugal (Antunes et al., 1981), así como en el Mioceno Medio de Austria (Schultz, 1978). El presente registro, constituye el primer registro de dicho género en América Central y probablemente del continente americano. En la actualidad este género tiene una distribución Pantropical.

Paleoecología: teniendo en cuenta las especies actuales del género Acanthurus se puede interpretar un paleoambiente tropical, profundidades de entre 10 y $15 \mathrm{~m}$, asociado a arrecifes de coral y hábitos de alimentación herbívoros, principalmente algas filamentosas (basado en Randall, 2001).

Familia SCARIDAE Rafinesque, 1810

\section{Género Pacuarescarus género nuevo}

Especie tipo Pacuarescarus kussmauli género y especie nueva

Etimología: "Pacuare" en referencia al río del mismo nombre + "Scarus" del griego antiguo pez loro + kussmauli en dedicatoria al Dr. Siegfried Kussmaul por su valioso aporte a la geología costarricense.

Holotipo: CFM-5121 (fig. 11: 1a-d).

Paratipos: CFM-5180 (no ilustrado); CFM5122 (fig. 11: 2); CFM-5123 (fig. 11: 3).

Material: varios fragmentos de baterías dentarias faríngeas superiores CFM-5121 (fig.11: 1) y CFM-5180, así como dentículos aislados CFM-5122 y CFM-5123 (fig. 11: 2 y 3, respectivamente) y CFM-5124, CFM-5125, CFM-5126,
CFM-5127, CFM-5128, CFM-5129, CFM-5130, CFM-5131 y CFM-5132 (fig. 12: 3, 4, 5, 6, 7, 8, 9, 10 y 11 , respectivamente).

Diagnosis: placas dentarias faríngeas superiores constituidas por 3 hileras de dentículos alargados internos que se alternan con 2 hileras de dentículos cortos marginales. Los dentículos alargados presentan un contorno elíptico elongado, ligeramente sigmoide y deprimido en su porción media; en su superficie dorsal portan una cresta longitudinal y su contorno lateral varía de cuasi-rectangular a ovalado. Los dentículos cortos presentan un contorno ovalado que varía a ligeramente rectangular y un contorno lateral elevado, triangular con vértices redondeados.

Discusión: el patrón de placas faríngeas superiores compuestas de dos hileras de dentículos es indicativo de la Familia Scaridae; además, el hecho de que los dentículos internos sean notablemente más grandes que los dentículos externos más pequeños, permite deducir que se trata de placas faríngeas correspondientes a formas muy cercanas al género actual Cetoscarus.

Distribución paleobiogeográfica: Mioceno Inferior de la Formación Río Banano, Costa Rica.

Paleoecología: por tratarse de una especie estrictamente fósil afín al género actual Cetoscarus y teniendo en cuenta la sedimentología del yacimiento, se puede asumir que se trata de una especie de pequeño tamaño que habitó los arrecifes de coral a profundidades no mayores a los $30 \mathrm{~m}$.

Scaridae indet.

Morfotipo 1

Material: 4 dientes caniniformes del dentario, con los códigos CFM-5133, CFM-5134, CFM5135 y CFM-5136 (fig. 7: 1, 2, 3 y 4, respectivamente).

Descripción discusión: dientes cónicos muy bajos, ligeramente ensanchados en la base y volcados, con cinta basal. Estos dientes son muy similares a los observados en varios géneros de Scaridae actual, por si solos no es posible asociarlos a ningún género en particular. 
Morfotipo 2

Material: 6 dientes caniniformes de la premaxila, con los códigos CFM-5137, CFM-5138 y CFM-5139 (fig. 7: 5, 6 y 7, respectivamente) y CFM-5140, CFM-5141 y CFM-5142 no ilustrados.

Descripción: dientes cónicos elongados y curvos, ligeramente cilíndricos en la parte media, con ápices redondeados volcados.

Discusión: estos dientes son muy similares a los observados en varios géneros de Scaridae actual, por si solos no es posible asociarlos a ningún género en particular.

Dientes faríngeos de Scaridae indeterminado

Material: 2 dientes faríngeos indeterminados CFM-5143 y CFM-5144 (fig. 9: 8-9).

Descripción: dentículos de contorno basal elíptico elongado, comprimido antero-posteriormente y con corona elevada. La corona presenta un contorno trapezoidal con bordes redondeados y una pequeña plataforma basal.

Discusión: los dientes descritos recuerdan a los dientes faríngeos de varias especies actuales de Scaridae como Cetoscarus y Sparisoma, sin embargo la falta de caracteres específicos no permite asignarlos a alguno de dichos géneros.

Familia LABRIDAE Cuvier, 1817

Género Labrodon Gervais, 1857

\section{Labrodon pavimentatum Gervais, 1857}

1957 Labrodon pavimentatum Gervais. Leriche, p. 48, lám. IV, fig. 15-18.

1968 Labrodon pavimentatus Gervais 1859.

Menesini, p. 44, tab. VI, fig. 17.

2003 Labrodon multidens Münster 1846. Vicens \& Rodriguez-Perea, p. 127, fig 20.

2012 Labrodon pavimentatum Gervais 1857.

Betancort Lozano, p. 280, lám. 26, figs. 7a-c.

Material: 1 placa dental faríngea y una docena de dientes aislados.
Descripción: el CFM-5145, corresponde a una placa faríngea superior, constituida por varias hileras de dientes rectangulares con los bordes redondeados y ligeramente acinturados y en algunos casos sigmoides (ver fig. 13: 1a-1d).

Los dientes faríngeos inferiores centrales del borde anterior son trapezoidales alongados, ejemplar CFM-5161 (fig.12:1) y CFM-5181(fig. 12:2), a rectangulares con bordes redondeados y ligeramente inflados, ejemplares CFM-5146, CFM-5147, CFM-5148, CFM-5149 y CFM-5150 (fig. 11: 4, 5, 6, 7 y 8 , respectivamente) en tanto que los dientes próximos a las márgenes tienden a ser cuadrados subcirculares, como es el caso del ejemplar CFM-5151 (fig.11: 9).

Discusión: Dica (2002), considera que el género Labrodon fue creado para incluir todas aquellas formas fósiles desconocidas que teóricamente podrían pertenecer a la familia Labridae. A pesar de ello, en la especie Labrodon pavimentatum Gervais, 1857, la placa faríngea inferior, presenta una característica única como lo es la presencia en la región central del borde inferior de un agrupamiento denticular en forma triangular (Betancort Lozano, 2012).

Distribución paleobiogeográfica: el género Labrodon se ha registrado en el Oligoceno Inferior de la cuenca de París (Merle et al., 2002), Mioceno de Australia (Fitzgeral, 2004); Mioceno Inferior de la Patagonia Argentina (Cione, 2002); la especie Labrodon pavimentatum Gervais, 1857, se registra frecuentemente en los depósitos de edad Mio-Plioceno de Europa (Zbyszewski \& D’Almeida, 1950; Serralheiro, 1954; Antunes et al, 1981; Menesini, 1968; Marsili et al., 2007; Bauzá, 1948; Bauzá \& Plans, 1973; Pawlowska, 1960; Vicens \& RodríguezPerea, 2003).

Paleoecología: en general y de acuerdo a Betancort Lozano (2012), los Labridae se caracterizan por ser peces de pequeño tamaño, forma más o menos alargada, comprimidos lateralmente, boca pequeña y protráctil. Suelen encontrarse en la zona infralitoral y se alimentan de pequeños invertebrados como moluscos o crustáceos. Esta familia se caracteriza por la presencia de dos huesos faríngeos inferiores. 

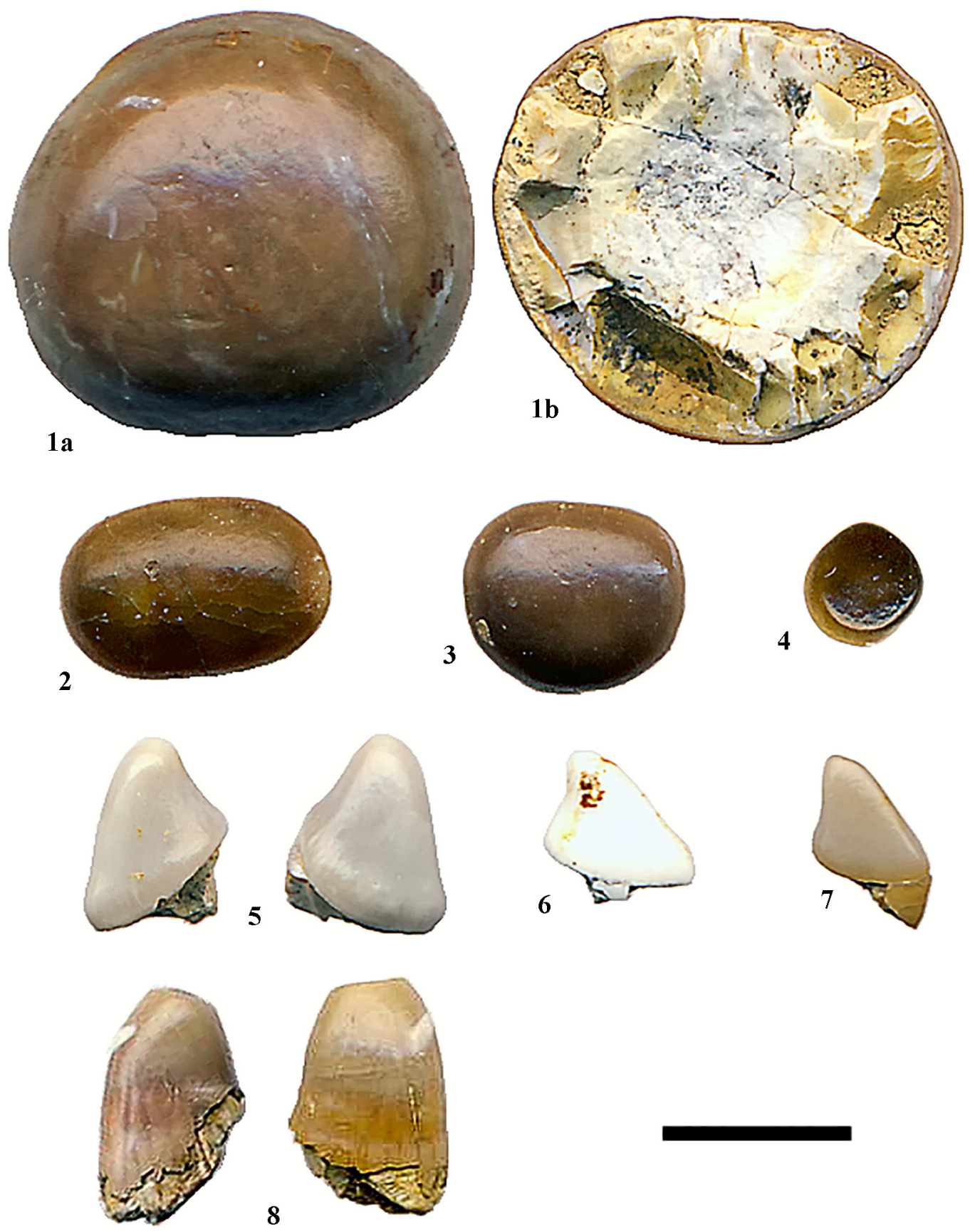

Fig. 6: Sparus sp 1., 1. diente posterior, 2 y 3. dientes de la segunda fila, 4. diente próximo a la sínfisis y 8. diente caniniforme; Pagrus pagrus (Linnaeus, 1785), 5 - 7. coronas de dientes caniniformes anteriores de posición incierta. La escala equivale a $0,5 \mathrm{~cm}$. 

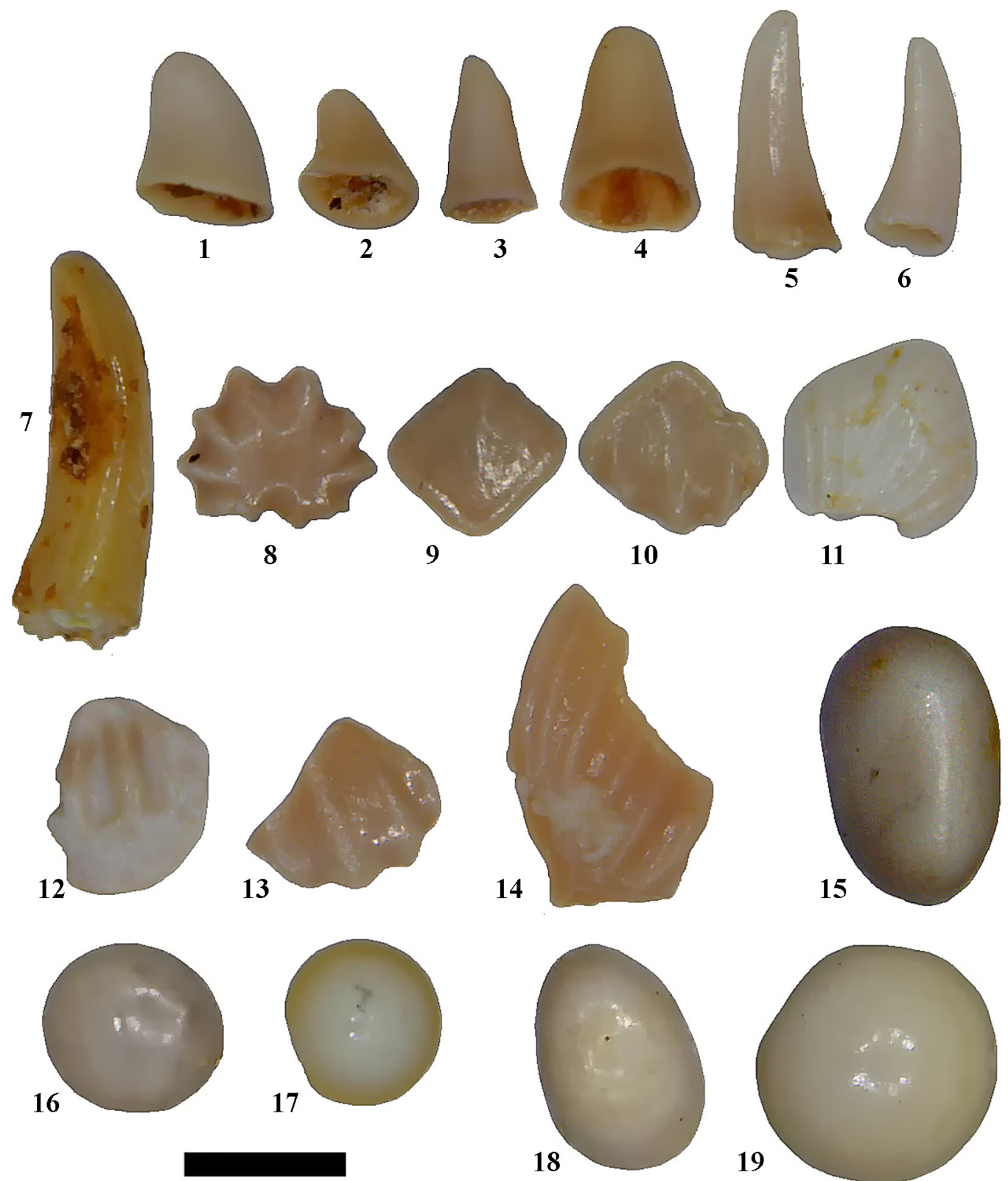

Fig. 7: dientes caniniformes de Scaridae indet., 1-4. MF 1 y 5-7. MF 2; diferentes morfotipos de escamas dérmicas de: 8 . raya indet, 9-14. tiburón indet., 15-19. Sparus sp. 2; Escala 0,5 mm. 


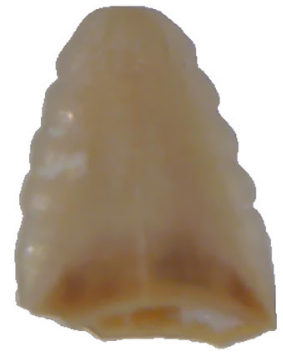

1

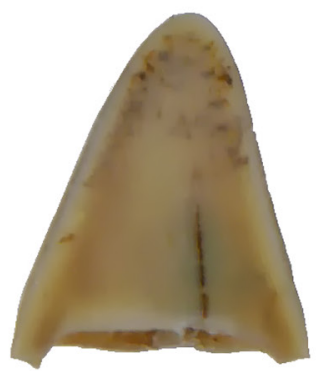

5

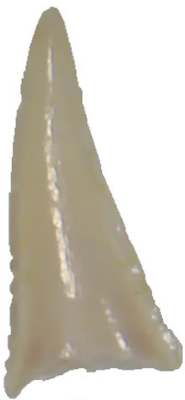

9

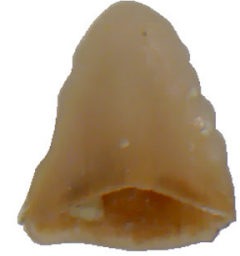

2

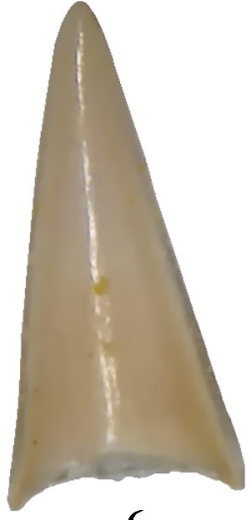

6

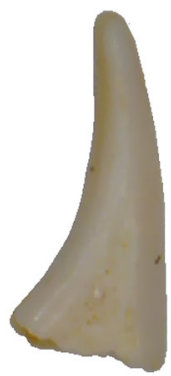

10
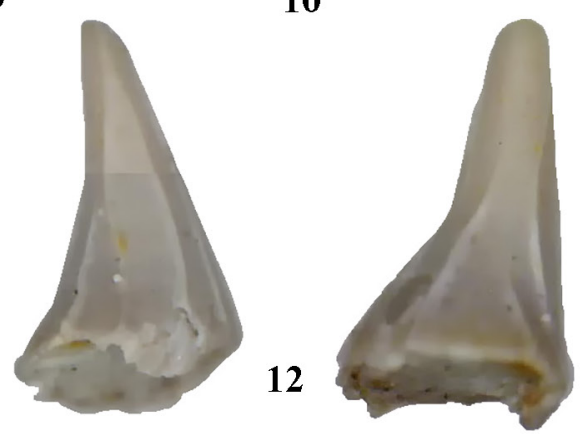

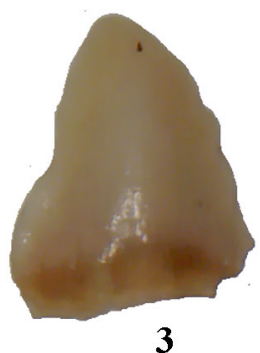

3

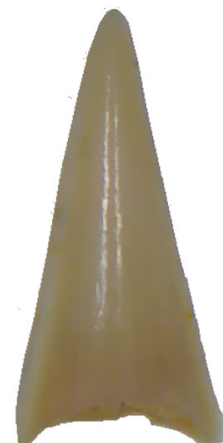

7
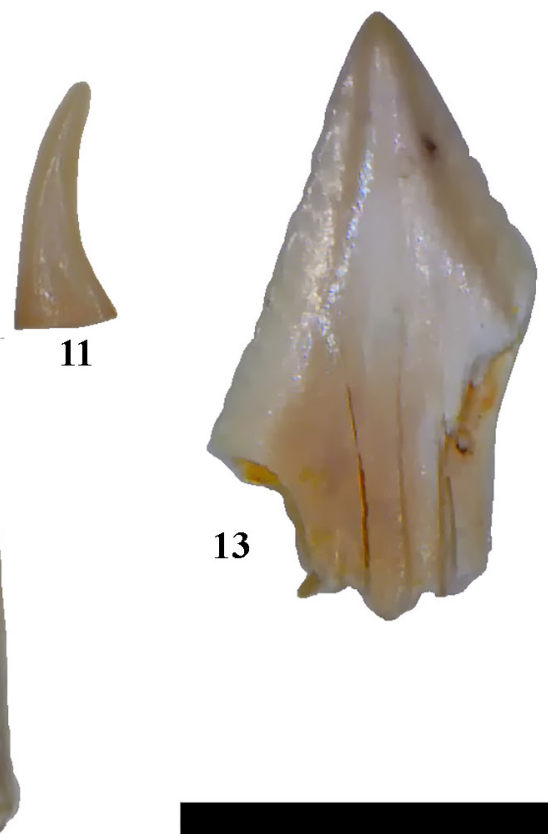

Fig. 8: Carcharhinidae indet: 1-4. Morfotipo 1 y 5. Morfotipo 2; 6-8. Sphyraena sp. Morfotipo 1, 9. Sphyraena sp. Morfotipo 2; 10-11; Dentex fossilis Jonet 1975,12, Balistes sp.; 13, Teleostei indeterminado. Escala $1 \mathrm{~mm}$. 

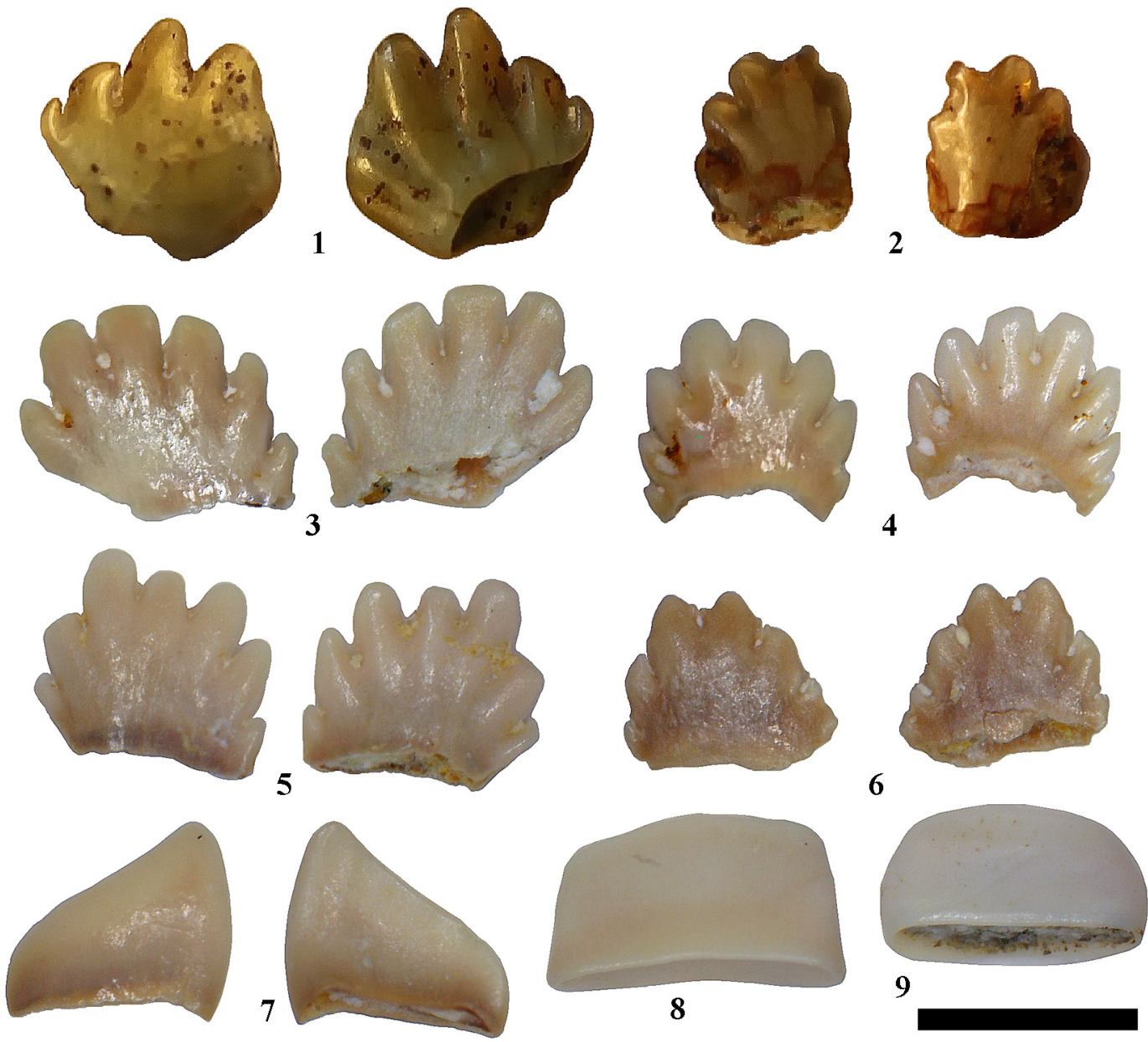

Fig. 9: Acanthurus sp., 1-6; Trigonodon jugleri, 7, en vistas labial y lingual y Scaridae indet. dientes faríngeos 8-9. Escala $1 \mathrm{~mm}$.

Subfamilia TRIGONODONTINAE Arambourg, 1927

(sin. PSEUDODACINAE Norman, 1957)

Género Trigonodon Sismonda, 1847

Trigonodon jugleri (Münster, 1846) sensu Schultz \& Bellwood, 2004

Material: 1 diente mandibular probablemente inferior CFM-5153 (fig. 9: 7), un fragmento de placa faríngea inferior CFM-5154 (fig. 13: 2) y varios fragmentos de baterías dentarias faríngeas superiores CFM-5155 y CFM-5156 (fig. 10: 1-2, respectivamente), así como dentículos sueltos, ejemplares CFM-5157, CFM-5158, CFM-5159 y CFM-5160 (fig. 10: 3, 4, 5 y 6, respectivamente).

Descripción: el CFM-5153 (fig. 9: 7) corresponde a un diente mandibular de contorno triangular redondeado, la cara externa es convexa y la interna cóncava. El CFM-5154 (fig. 13: 2), corresponde a un fragmento posterior de una placa faríngea inferior, constituida por dientes de contorno elíptico a redondeado, superpuestos en varias capas. Estos dientes se caracterizan por ser bajos, tersos y poseer paredes muy gruesas.

Discusión: hasta hace relativamente poco se aceptaba que las especies fósiles Trigonodon oweni incluida en la Familia Trigonodontidae 
y Asima jugleri incluida en la Familia Labridae eran especies distintas, pero Schultz \& Bellwood (2004), lograron demostrar de que se trata de la misma especie denominada Trigonodon jugleri y la incluyeron en la familia Labridae.

Por su parte, el diente mandibular acá descrito es característico de este género de lábrido, diferenciable fácilmente de los dientes similares de Diplodus sp. por ser estos últimos más altos, inflados y redondeados (Schultz \& Bellwood, 2004). En el caso del fragmento de placa faríngea inferior, se diferencia de otras baterías de dientes faríngeos presentes en la familia Scaridae, por contener varias capas de dentículos con paredes muy gruesas, estos además están dispuestos de manera desordenada. Por otra parte, las baterías dentarias faríngeas superiores de Trigonodon, se diferencian de las homólogas presentes en los Scaridae, porque en ésta última familia cada dentículo conforma una unidad independiente unida de manera inmediata a los otros dentículos, y además, cuentan con dentículos laterales más pequeños y en Trigonodon la unión de los dentículos deja un espacio entre ellos que está relleno con cemento y carecen de dentículos marginales.

Distribución paleobiogeográfica: el género Trigonodon y la especie Trigonodon jugleri (Münster, 1846) ha sido comúnmente registrado en el Mioceno de Portugal, España, Francia, Italia, Eslovaquia y Austria (Serralheiro, 1954; Bauzá \& Plans, 1973; Jonet et al., 1975; Leriche, 1957; Marsili et al., 2007; Menesini, 1968; Schultz, 1978; Schultz \& Bellwood, 2004; Sismonda, 1861). Los registros más antiguos corresponden al Mioceno Inferior de Italia y Austria (Schultz \& Bellwood, 2004).

Paleoecología: peces omnívoros tropicales y subtropicales, habitantes comunes en fondos rocosos y arrecifes coralinos a profundidades no mayores a los $40 \mathrm{~m}$; suelen alimentarse los juveniles de parásitos de otras especies y los adultos prefieren las algas incrustantes (Schultz \& Bellwood, 2004).
Familia Sphyraenidae Rafinesque, 1815

Género Sphyraena Walbaum, 1793

Sphyraena sp.

Material: 4 dientes

Descripción: coronas triangulares muy altas y angostas, biconvexas: morfotipo 1 con filos lisos, ejemplares CFM-5162, CFM-5163 y CFM-5164 (fig. 8: 6, 7 y 8) o morfotipo 2 con filos ligeramente aserrados, ejemplar CFM-5165 (fig. 8: 9).

Discusión: el material acá descrito no difiere de las formas de Sphyraena descritas por Casier (1966) para la Formación Océanique en el Cenozoico de la Isla de Barbados y que probablemente se trata de formas juveniles. De hecho el morfotipo 1 recuerda a la especie Sphyraena sp. y el morfotipo 2 a la especie Sphyraena senni.

Distribución paleobiogeográfica: el género Sphyraena se ha registrado en numerosas localidades de Europa y Norte América (Laurito, 1999), en el Caribe se registra en el Terciario de Cuba (Díaz-Franco \& Rojas-Consuegra, 2009); en el Oligoceno Superior-Mioceno Inferior de las Formaciones Castillo, Cantaure, San Lorenzo y Mioceno Superior - Plioceno Inferior de la Formación Codore todas en Venezuela (Aguilera, 2010; Aguilera \& Lundberg, 2010); en el Mioceno de la Formación de Tamana en la Isla de Trinidad y la Formación Océanique de la Isla de Barbados (Casier, 1958); en el Plioceno de la República Dominicana en la Formación Gurabo (Nolf \& Stringer, 1992) y Jamaica en la Formación Borden (Stringer, 1998).

La especie Sphyraena barracuda Walbaum 1792 se registra en el Mioceno Medio de la Formación Gatún en Panamá (Gillette, 1984) y el Mioceno Superior - Plioceno Inferior de Costa Rica en la Formación Uscari (Laurito, 1999), donde también, se describen otros especímenes asociados de Sphyraenidae indeterminado cuyas coronas recuerdan al morfotipo 2 de la presente localidad y a la especie Sphyraena senni de la Formación Océanique del Mioceno de la Isla de Barbados. 
Orden TETRAODONTIFORMES Berg, 1940

Familia BALISTIDAE Risso, 1810

Género Balistes Linnaeus, 1758

\section{Balistes sp.}

Material: 1 diente con el número de catálogo CFM-5166 (fig. 8: 12).

Descripción: diente de corona alta con ápice angosto, redondeado y volcado, con la base ancha, piramidal y facetada.

Discusión: el ejemplar arriba descrito corresponde a un diente parasinfisial de un juvenil de Balistes sp.; no siendo posible asignarlo a una especie en particular.

Distribución paleobiogeográfica: la especie Balistes crassidens fue descrita para el Mioceno de la Formación de Tamana en la Isla de Trinidad (Casier, 1958). El presente hallazgo, constituye el segundo registro fósil del género Balistes en el Caribe.

Paleoecología: el género Balistes está constituido por especies predominantemente bentónicas, común en arrecifes de coral y fondos rocosos a lo largo de la costa y a profundidades menores a los $100 \mathrm{~m}$. Se alimenta de invertebrados que habitan dichos fondos endurecidos, principalmente moluscos y cangrejos, además de zooplancton (sensu Matsuura, 2001).

\section{Ictiolitos}

Además de los dientes de peces cartilaginosos y óseos arriba descritos, se recuperaron 7 ejemplares de ictiolitos, constituidos por dientes dérmicos de tiburón y raya y 6 dientes orales de tiburón, así como una decena de dientes de peces óseos, todos ictiolitos no determinables taxonómicamente.

Escamas placoides de coronas bajas, ligeramente más altas que sus raíces y de superficies muy amplias, fuertemente acanaladas con esmalte liso y brillo céreo. Se reconocieron los siguientes morfotipos:
Semicircular plano simétrico con 6 cóstulas radiantes y muesca posterior. Este morfotipo recuerda los dientes dermales de los Batoidea, ejemplar CFM-5167 (fig. 7: 8).

Romboide simétrico con quilla central con reborde marginal y esquinas redondeadas, ejemplar CFM-5168 (fig. 7: 9).

Romboide asimétrico con quilla central con reborde marginal y una cóstula a cada lado, ejemplar CFM-5169 (fig. 7: 10).

Romboide simétrico con quilla central sin reborde marginal y con 3 cóstulas a cada lado, ejemplar CFM-5170 (fig. 7: 11).

Subcircular irregular con quilla central prominente y una cóstula gruesa a cada lado, ejemplar CFM-5171 (fig. 7: 12).

Subcircular acanalado sin quilla central con 4 cóstulas conspicuas, ejemplar CFM-5172 (fig. 7: 13).

Deltoide acanalado simétrico con prominente úvula central en la cara anterior con 3 costillas en la porción derecha e izquierda, ejemplar CFM5173 (fig. 7: 14).

A excepción del primer morfotipo todos los demás corresponden a escamas dérmicas de tiburones.

Dientes orales de Carcharhinidae indeterminado: coronas de dientes aislados de forma triangular, biconvexas, con presencia de cuello lingual (fig. 8: 1-5). Estos dientes en general corresponden a formas juveniles de Carcharhinidae, debido a ello es muy difícil asignarlos a un taxón determinado, sin embargo se observan dos morfotipos:

Morfotipo 1: presentan coronas con filos aserrados, ejemplares CFM-5174, CFM-5175, CFM5176 y CFM-5177 (fig. 8: 1, 2, 3 y 4, respectivamente).

Morfotipo 2: presentan coronas con filos lisos, ejemplar CFM-5178 (fig. 8: 5).

Teleostei indet: el CFM- 5182 (fig. 8: 13), corresponde a un fragmento de corona triangular con las caras labial y lingual planas, filos hundidos y finamente aserrados. 


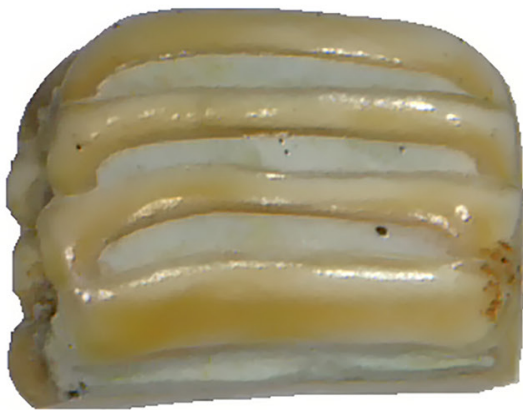

$\mathbf{a}$

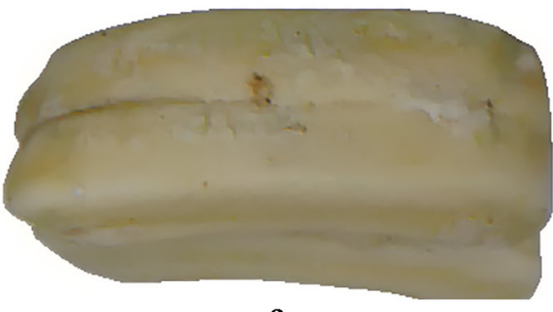

a

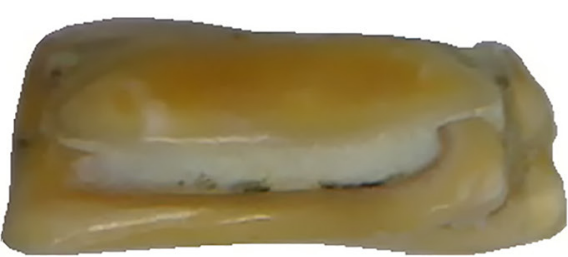

c
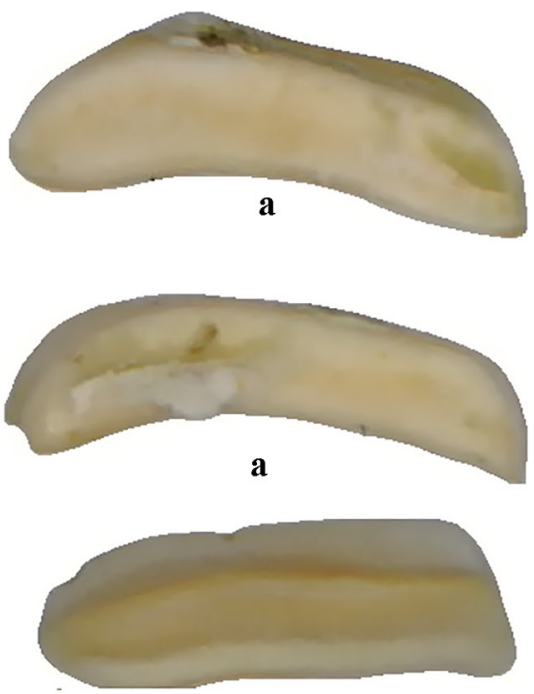

a
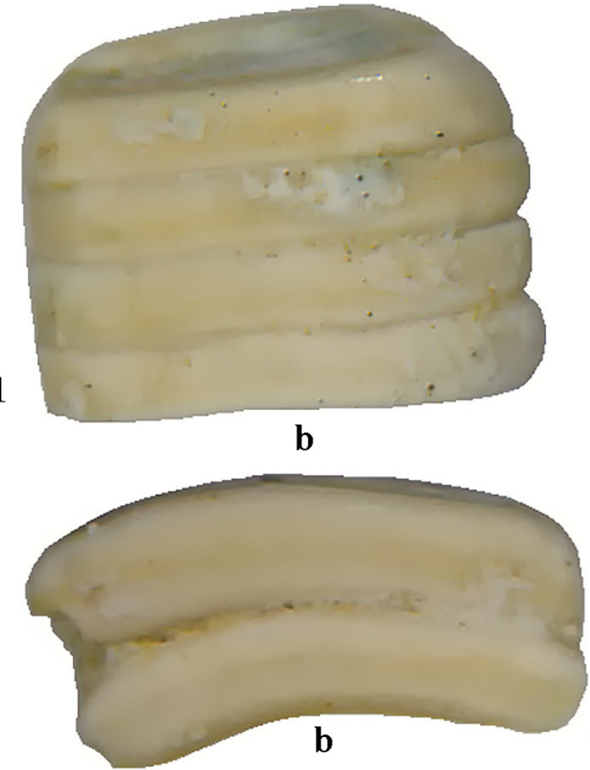

2

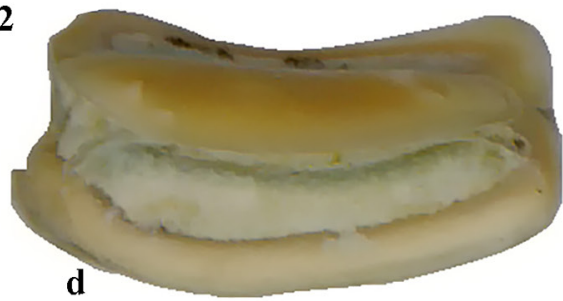

3

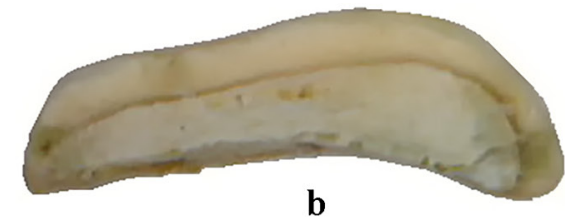

4

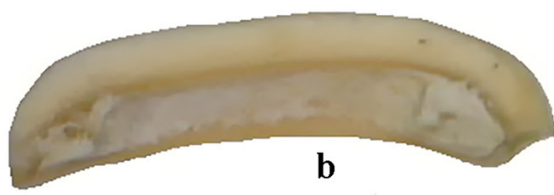

a.

b

Fig. 10: Dientes faríngeos superiores de Trigonodon jugleri, en vistas orales: 1a, 2c -d, 3b y 4b; basal: 1b, 2a, 5 y 6; lateral 2b, 3a y 4 a. Escala $0,5 \mathrm{~cm}$. 

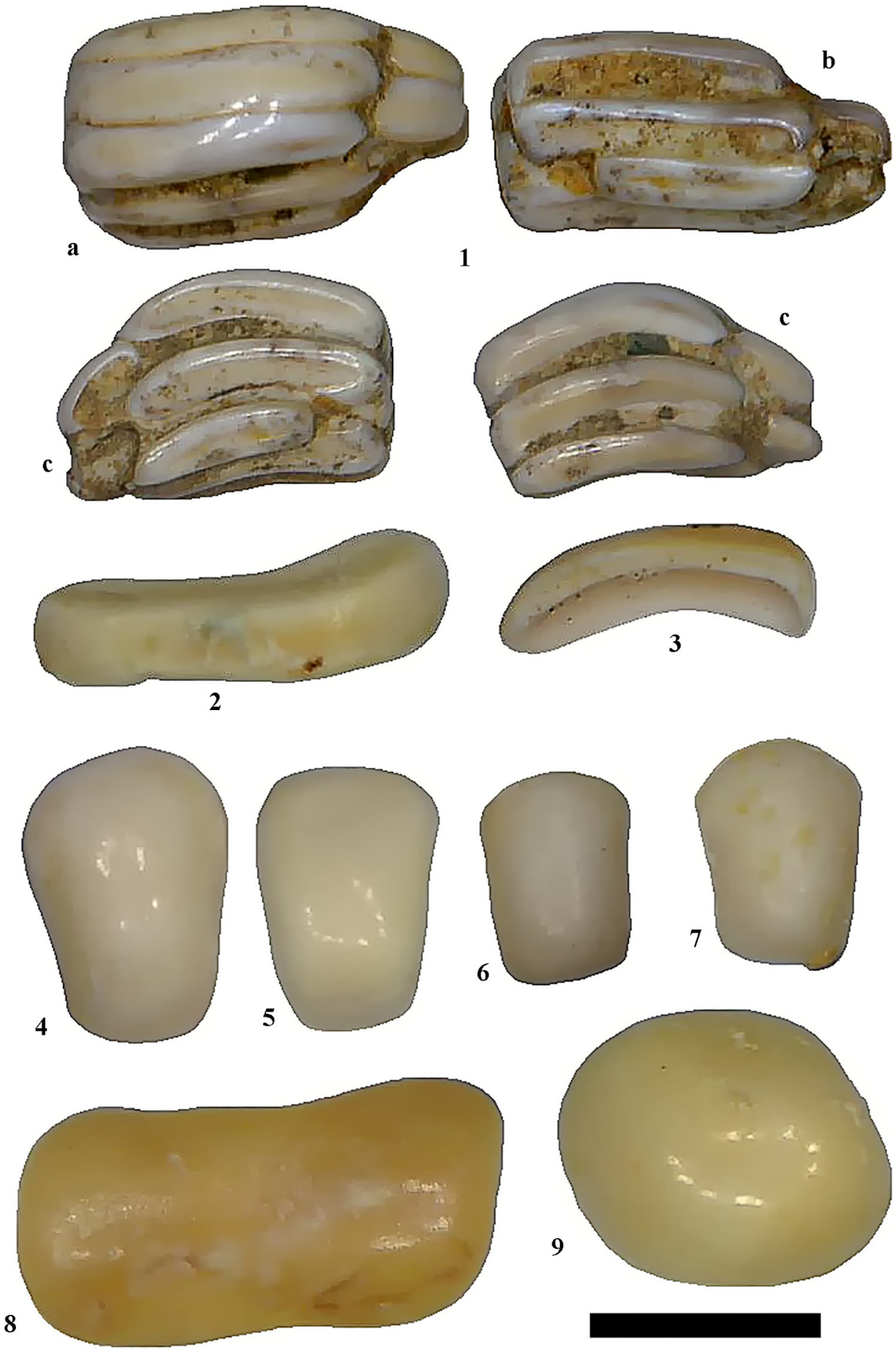

Fig. 11: Dientes faríngeos superiores de Pacuarescarus kussmauli sp.nov. en vistas: 1a. oral, basal 1b y laterales 1c-d. 2-3 Dentículos aislados Pacuarescarus kussmauli sp.nov. 4-9. Labrodon pavimentatum, dentículos faríngeos inferiores. Escala 0,5 cm. 

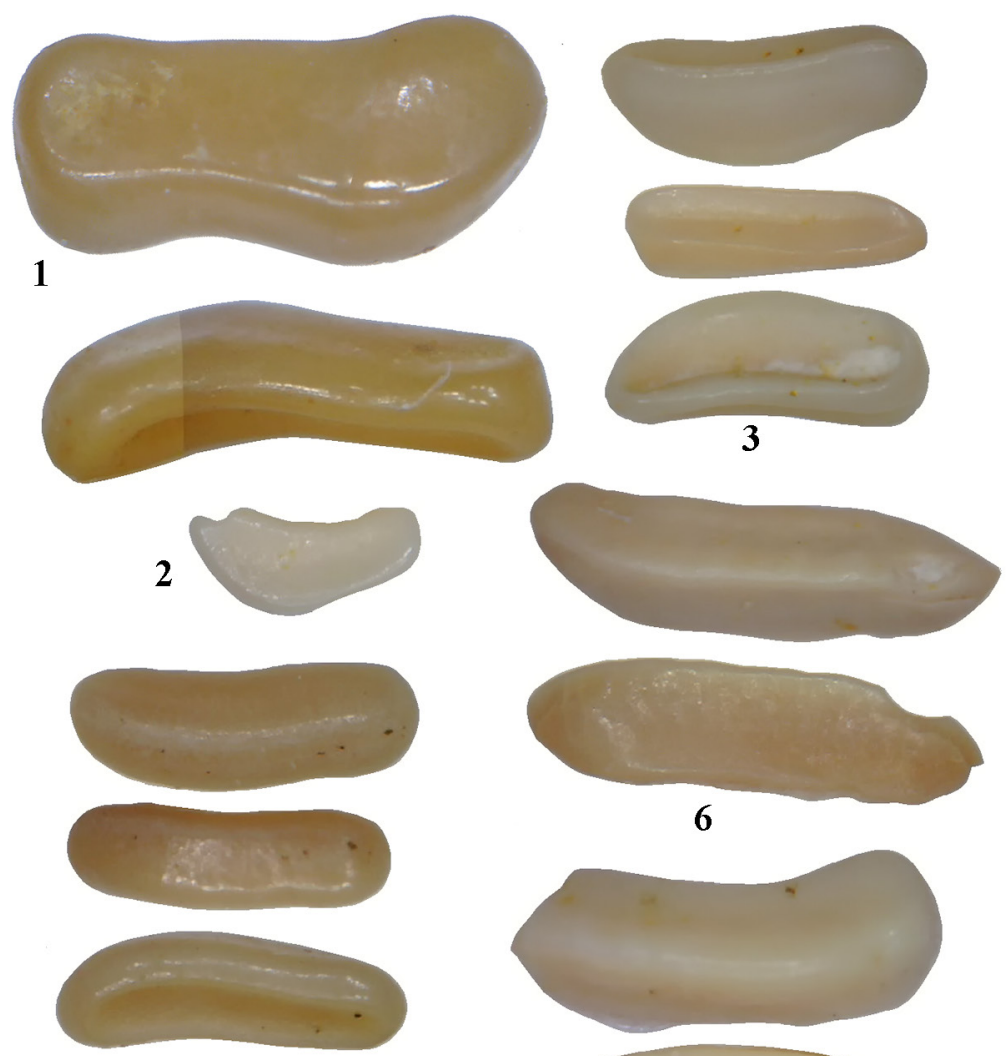

8

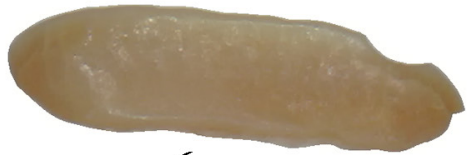

6

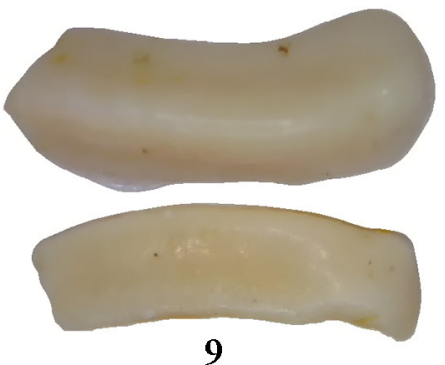

9

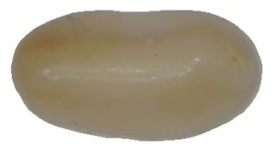

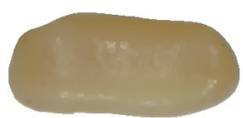

7

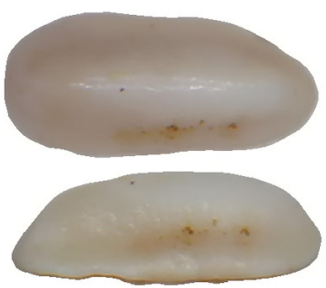

11

Fig. 12: Dientes faríngeos de: 1-2. Labrodon pavimentatum, dentículos faríngeos superiores. 3- 11. Pacuarescarus kussmauli sp. nov. Escala $1 \mathrm{~mm}$.

\section{DISCUSIÓN Y CONCLUSIONES}

Edad: de acuerdo con la información geológica, sedimentológica y micropaleontológica analizada y descrita por Fernández (1987), la localidad del yacimiento de Pacuare donde se recolectaron los restos de peces, presenta litologías muy similares a las descritas para los afloramientos de la Formación Río Banano en la sección próxima a la intersección entre las quebradas Grande y
Gata. Dichos afloramientos se ubican unos 1100 $\mathrm{m}$ al norte del área de estudio. Alrededor de ese afloramiento, Fernández (1987) obtuvo una edad Mioceno Inferior según las muestras FG466, FG-472 y FG-477 todas recolectadas en la Formación Uscari.

La Formación Uscari en esta zona se interdigita con la Formación Río Banano y teniendo en cuenta la estratigrafía, se concluye que la edad de la fauna es Mioceno Inferior. La distribución 

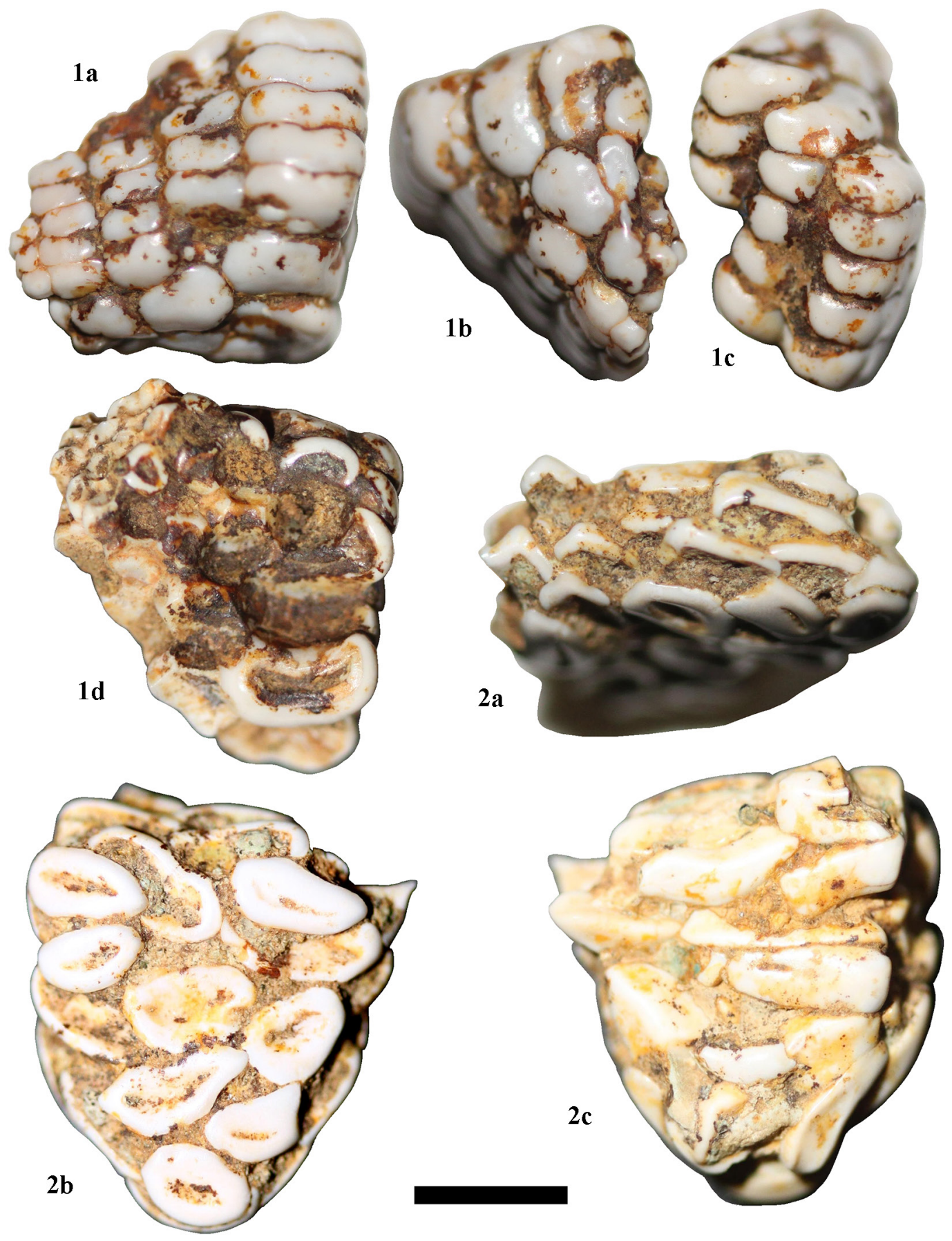

Fig. 13: 1. Labrodon pavimentatum, batería faríngea superior en vistas: a y c. lateral, b. externa y d. basal; 2. Trigonodon jugleri (Münster, 1843), extremo anterior de batería faríngea inferior, a. lateral, b. basal y c. externa. Escala 0,5 cm. 
Cuadro 1

Distribución paleobatimétrica y biogeográfica de los diferentes taxa fósiles, recolectados en la localidad de Tres Equis de Pacuare, Formación Río Banano. La banda gris, corresponde a la zona fótica, profundidad donde se da el desarrollo de corales coloniales. Las líneas continuas indican las profundidades en las que habitan o frecuentan los representantes actuales y en el caso de las líneas discontinuas los rangos de profundidad infrecuente u ocasional. Simbología: A con representantes actuales; F

fósiles; P Pantropicales y C Cosmopolitas (tropicales + subtropicales).

T axa

\section{Chondrichthyes \\ Hexanchidae \\ Heptronchias perlo \\ Otodontoidea}

Megaselachus subauriculatus

Lamuidae

Isurus oxyrhinc hus

Odontaspidae

Carchorias acutissima

Mitsulsurinidae

Mitsukurina sp.

Hemigaleidae

Hemipristis serra

Carcharhinidae

Ne gaprion eury bathrodon

Carcharhinus sp.

\section{Ac tinop terygii}

Sparidae

Diplodus jomnitonus

Sporus sp. 7

Sporus sp. 2

Pagrus pagrus

Dentex fossilis

Ac anthuridae

Acconthurus sp.

Scaridae

Pacuarescorus kussmauli

Labridae

Labrodon povimentatum

Trigonodon jugleri

Sphyraenidae

Sphyraena sp.

Tetraodontidae

Balistes $s p$
Batimetría (m)

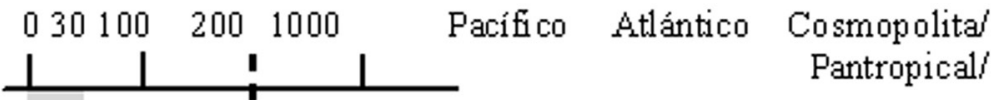

F/A
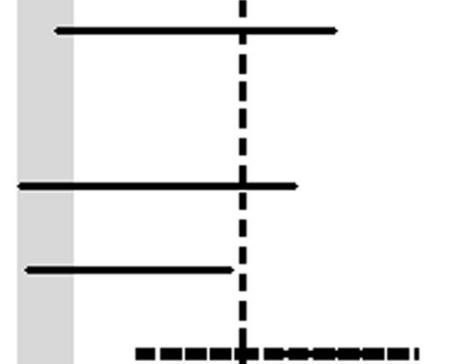

F/A

F/A

F/A

F

F/A

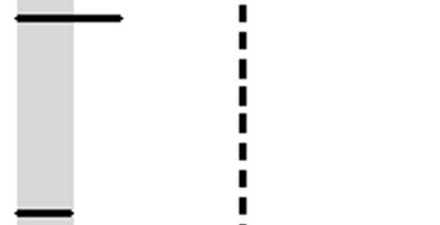

F

$F$

F/A

F/A

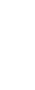

$-$

$-$

F

A

A
Biogeografía

\section{Pantropical/}

F/A

P

F

P

F/A

P

F/A

C

F/A

C

F

C

F/A $\quad P$

F P

F

F/A

$\mathrm{F} / \mathrm{A}$

$P$

P

$P$

F

P

F

P

F

F

C

C 
bioestratigráfica de la asociación de tiburones sugiere un rango muy amplio de edad correspondiente a todo el Mioceno.

La fauna de seláceos de la localidad de Tres Equis de Pacuare, se caracteriza por tiburones cosmopolitas, propios de las aguas tropicales y subtropicales de las plataformas continentales e insulares y del talud continental, lo que es típico de las faunas de seláceos del Mioceno.

De todos los seláceos, las especies Megaselachus subauriculatus (Agassiz, 1838) e Isurus oxyrinchus Rafinesque, 1810 se sabe fueron fuertes nadadores pelágicos; Hemipristis serra Agassiz, 1835 y Negaprion eurybathrodon (Blake, 1862) probablemente frecuentaban el pelágico durante sus migraciones como lo hacen los tiburones del género Carcharhinus (Cuadro 1).

Por su parte, el hallazgo de Heptranchias perlo (Bonaterre, 1788) junto con Mitsukurina sp., ambas especies de mar profundo y comunes en el talud continental, deben interpretarse como ocasionales visitantes de la zona nerítica. Probablemente, la plataforma continental del arco de islas en esa época debió ser relativamente angosta y se encontraba rodeada de mares profundos que facilitaron la migración de estas especies entre el Caribe y el Pacífico Oriental.

La especie Carcharias acutissima (Agassiz, 1843) es la segunda vez que se registra en el Caribe de América Central y aunque su registro en el Mioceno del Caribe sugiere una amplia distribución geográfica en esa región, la especie actual Carcharias taurus Rafinesque, 1810 no habita el Caribe o la costa Pacífica de América del Sur (sensu Cione et al., 2007), ni de América Central, lo que confirma su salida del Caribe al final del Mioceno o durante el Plioceno Inferior; ello verifica la teoría de Cione et al. (2007) sobre la posible extirpación del género de estas áreas, debido a una reducción de las plataformas continentales e insulares en el Plioceno Medio por una consecución de caídas en el nivel de los mares.

Los peces óseos por su parte, constituyen una importante asociación de peces de arrecife, lo cual permite determinar de manera indirecta pero muy exacta la existencia de antiguos arrecifes de coral en la Formación Río Banano, lo que es coincidente con una de las cinco facies de la Formación Río Banano definidas por Taylor (1975).

Como en el caso arriba citado del tiburón Carcharias acutissima (Agassiz, 1843), el hecho de que no se registre en la actualidad, ninguna especie del género Diplodus en el Caribe centroamericano o en el Interior de la Cuenca del Caribe, probablemente se debió a un cambio ambiental drástico que pudo ser causado por varios factores, entre los que se presume el aumento de la salinidad y la caída de la temperatura de sus aguas superficiales durante el Plioceno Inferior, eventos asociados con el cierre del Istmo de Panamá (sensu Gussone et al., 2004) y/o a una reducción de las plataformas continentales por una serie sucesiva de variaciones en el nivel del mar según la hipótesis de Cione et al. (2007).

En general, las especies de peces óseos como Pagrus pagrus (Linnaeus, 1758), Diplodus jomnitanus Valenciennes, 1844 y Sparus spp., sugieren aguas cálidas que junto con la mayoría de la fauna de seláceos suponen una salinidad normal. El tipo durófago de batería dentaria que presentan estos peces, confirma su dieta a base de crustáceos, dieta que comparten con los tiburones Carcharias acutissima (Agassiz, 1843) y Negaprion eurybathrodon (Blake, 1862).

En tanto, el registro de los géneros Trigonodon, Acanthurus y los peces loro Scaridae indeterminados y la especie nueva Pacuarescarus kussmauli, confirman la existencia de fondos duros sublitorales y de arrecifes de coral, pues todos estos géneros evidencian una asociación de especies de arrecifes que se alimentan de algas incrustantes (ver tabla 1). Esto se verifica con el hallazgo de corales coloniales retrabajados y transportados asociados con la ictiofauna.

En relación con el registro del género Labrodon que aunque no cuenta con representantes actuales, se deduce que fueron peces sublitorales que habitaron las plataformas insulares y continentales en mares tropicales y subtropicales, asociados a arrecifes de coral, cuya dentición faríngea durófa- 
ga se interpreta como la de un organismo que se alimentaba de moluscos de concha dura, erizos y crustáceos (sensu Dica, 2002).

Por otra parte, Pacuarescarus kussmauli género y especie nueva debe ser considerada por ahora, como el registro fósil más temprano que se tenga de la Familia Scaridae. Antes del presente hallazgo, la especie Calotomus preisli Bellwood \& Schultz, 1991 del Mioceno Medio de Austria, fue considerada la especie más antigua de dicha familia (Bellwood, 1994) y por lo tanto se aceptó que los Scaridae se establecieron aproximadamente para la época del cierre del Tethys Oriental. Por lo tanto, se acepta que la región del Tethys Central o Paratethys fue clave en la evolución de la familia, pues se asume que para el Mioceno Medio ya se había diferenciado taxonómicamente lo suficiente, pues registra el género actual Calotomus (sensu Bellwood \& Schultz, 1991; Bellwood, 1994).

Debido a lo anterior, Pacuarescarus kussmauli género y especie nueva es ancestral al género Calotomus y a todos los Scaridae conocidos con los que compartiría un ancestro común, y la región del Caribe o Tethys Occidental, la cual estaba conectada con el Pacífico Oriental, debe ser considerada en principio como la región de origen de los peces loro o Scaridae, lo que cambia parcialmente los esquemas cladogenéticos, biogeográficos y de dispersión previamente establecidos (Bellwood, 1994, Bellwood \& Schultz, 1991, Cowman \& Bellwood, 2011, 2013).

Una observación importante que se debe tener en cuenta es la especie Scaroides gatunensis Toula, 1909, descrita para el Mioceno del Canal de Panamá con base en dientes orales, que de acuerdo con Bellwood \& Schultz (1991) corresponden a un Diodontidae (fig. 3a-c de Toula, 1909) y no a un Scaridae. Siendo los Scaridae fósiles de la localidad de Tres Equis y de la Formación Río Banano, los únicos registros hasta ahora conocidos para el Cenozoico del Caribe.

En resumen se describen, 7 familias de tiburones con 8 géneros, destacando el registro de las especies Megaselachus subauriculatus (Agassiz, 1838) y Mitsukurina sp., y 6 familias de peces óseos, Sparidae con 4 géneros y 5 especies, Pagrus pagrus (Linnaeus, 1758), Diplodus jomnitanus Valenciennes, 1844, Sparus spp. y Dentex fossilis, y las familias Sphyraenidae, Tetraodontidae, Scaridae, Acanthuridae y Labridae, destacando las especies Balistes sp., Acanthurus sp., Pacuarescarus kussmauli; Labrodon pavimentatum y Trigonodon jugleri registradas por primera vez en América Central y el Caribe.

\section{AGRADECIMIENTOS}

Al Dr. David R. Bellwood, profesor de la School of Marine and Tropical Biology \& ARC Centre of Excellence for Coral Reef Studies de la James Cook University, Townsville, Queensland, Australia, quién gentilmente nos brindó gran cantidad de literatura y confirmó nuestra determinación acerca de una nueva especie de Scaridae fósil.

Al Dr. Ortwin Schultz del Naturhistorisches Museum in Wien, Austria, quién confirmó nuestra determinación de la especie de Trigonodon jugleri (Münster, 1846). A ambos nuestro más profundo agradecimiento.

\section{REFERENCIAS BIBLIOGRÁFICAS}

ADNET, S., 2006: Nouvelles faunes de sélaciens (Elasmobranchii, Neoselachii) de l'Eocène moyen des Landes (Sud-Ouest, France). Implication dans la connaisssance des communautés d'eaux profondes.- Palaeo Ichthyologica, 10: 1-128.

ADNET, S., ANTOINE, P.O., HASSAN BAQRI, S.R., CROCHET, J.Y., MARIVAUX, L., WELCOMME, J.L. \& MÉTAIS, G., 2007: New tropical carcharhinids (chondrichthyes, Carcharhiniformes) from the Late Eocene - Early Oligocene of Balochistan, Pakistan: paleoenvironmental and paleogeographic implications.- J. Asian Earth Sci. 30: 303-323.

AGUILERA, O.A., 2010: Peces fósiles de Venezuela.- 254 págs. Ed. GeoBio Consultores C.A., Venezuela. 
AGUILERA, O. \& RODRIGUES DE AGUILERA, D., 1999: Bathymetric distribution of Miocene to Pleistocene caribbean teleostean fishes from the coast of Panama and Costa Rica.- En: COLLINS, L.S. \& COATES, A.G., (eds): A paleobiotic survey of the caribbean faunas from the Neogene of the Isthmus of Panama.- Bull. Amer. Paleont. 357: 261-269.

AGUILERA, O. \& RODRIGUES DE AGUILERA, D., 2001: An exceptional coastal upwelling fish assemblage in the caribbean Neogene.- J. Paleont. 75(3): 732-742.

AGUILERA, O.A. \& LUNDBERG, J., 2010: Venezuelan, Caribbean and Orinocoan Neogene fish.- En: SÁNCHEZVILLAGRA, M.R.; AGUILERA, O.A. \& CARLINI, A.A., (eds): Urumaco and Venezuelan paleontology, the fossil record of the northern Neotropics.- Indiana Univ. Press. 129-152.

AGUILERA, O.A., GARCÍA, L. \& COZZUOL, M.A., 2008: Giant-toothed white sharks and cetacean trophic interaction from the Pliocene Caribbean Paraguaná Formation.Paläontologische Zeitschrift, 82(2): 204208.

AGUILERA, O.A., FEIJÓ, M.I., TAVARES, E., FERREIRA, S.A.R. \& SÁNCHEZVILLAGRA, M.R., 2011: The Neogene tropical America fish assemblage and the paleobiogeography of the Caribbean region.- Swiss J. Palaeontol. 130: 217-240.

ANTUNES, M.T., 1978: Faunes Ichthyologiques du Néogène Supérieur D’Angola, Leur Âge, Remarques sur le Pliocène Marin en Afrique Australe.- Ciências da Terra, 4: 59-90.

ANTUNES, M.T. \& JONET, S., 1970: Requins de l'Helvétien Supérieur et du Tortonien de Lisbonne.- Rev. Fac. Ciênc. Lisboa, 2da. Sér. C, XVI(1): 119-280.
ANTUNES, M.T. \& BALBINO, A,C., 2003: Uppermost Miocene lamniform selachians (Pisces) from the Alvalade basin (Portugal).- Ciências da Terra, 15: 141154.

ANTUNES, M.T., JONET, S. \& NASCIMENTO, A., 1981: Vertébrés (crocodiliens, poissons) du Miocène marin de l'Algarve occidentale.- Ciências da Terra, 6: 9-38.

APOLÍN, J., GONZÁLEZ BARBA, G. \& MARTÍNEZ, J., 2007: Seláceos del Mioceno de Quebrada Pajaritos (Piura, Perú).- XII Congreso Peruano de Geología. Resúmenes Extendidos, 401404.

ARAMBOURG, C., 1927: Les poissons fossiles d'Oran.- Matériaux pour la carte géologique de 1'Algérie, Paléontologie, Alger, 6: 1-293.

ASHBY, J.R., 1987: Paleoecología de vertebrados de la fauna local del Arroyo Salada del Pleistoceno Tardío, Baja California Sur, México.- Ciencias Marinas, 13: 2330 .

BAUZÁ, J., 1948: Nuevas aportaciones al conocimiento de la ictiología del Neógeno catalano-balear.- Estudios Geológicos, 8: 221-239.

BAUZÁ, J. \& PLANS, J., 1973: Contribución al conocimiento de la fauna ictiológica del Neógeno Catalano Balear.- Bol. de la Sociedad de Historia Natural de las Baleares, 28: 72-131.

BELLWOOD, D.R., 1994: A phylogenetic study of the parrotfishes family Scaridae (Pisces: Labroidei), with a revision of genera.- Rec. Aust. Mus. Suppl. (20): 84.

BELLWOOD, D.R., 1996: The Eocene fishes of Monte Bolca: the earliest coral reef fish assemblage.- Coral Reefs, 15: 11-19. 
BELLWOOD, D.R. \& SCHULTZ, O., 1991: A review of the fossil record of the parrotfishes (Labroidei: Scaridae) with a description of a new Calotomus species from the Middle Miocene (Badenian) of Austria.- Annalen Naturhistorisches Museum Wien, 92: 55-71.

BETANCORT LOZANO, J.F., 2012: Fósiles marinos del Neógeno de Canarias (Colección de la ULPGC): dos neotipos, catálogo y nuevas aportaciones (sistemática, paleoecología y paleoclimatología).- 413 págs. Univ. de Las Palmas de Gran Canaria, Gran Canaria [Tesis Ph.D.].

BIENKOWSKA-WASILUK, M. \& RADWANSKI, A., 2009: A new occurrence of sharks in the Menilite Formation (Lower Oligocene) from the Outer (Flysch) Carpathians of Poland.- Acta Geologica Polonica, 59(2): 235-243.

BLAKE, C.C., 1862: Sharks' teeth at Panama.The Geologist, 5: 316.

BOESSENECKER, R.W., 2011: A new marine vertebrate assemblage from the Late Neogene Purisima Formation in Central California, Part I: Fossil sharks, bony fish, birds, and implications for the age of the Purisima Formation west of the San Gregorio fault.- PalArch's J. Vertebrate Palaeontol. 8(4): 1-30.

BOLLIGER, T., KINDLIMANN, R. \& WEGMÜLLER, U., 1995: Die marinen Sedimente (jüngere OMM, St. Galler-Formation) am Südwestrand der Hörnlischüttung (Ostschweiz) und die palökologische Interpretation ihres Fossilinhaltes.- Eclogae Geologicae Helvetiae 88(3): 885-909.

CAPPETTA, H., 1970: Les sélaciens du Miocène de la région de Montpellier.- 139 págs Paleovertebrata, Mém. Extr.
CAPPETTA, H., 1987: Chondrichtyes II: Mesozoic and Cenozoic Elasmobranchii.En: SCHULTZE, H.P. (ed.): Handbook of paleoichthyology.- 193 págs.Vol. 3B.

CAPPETTA, H., 2012: Chondrichtyes Mesozoic and Cenozoic Elasmobranchii.- En: SCHULTZE, H.P. (ed.) : Handbook of Paleoichthyology, Vol. 3E: 1-512 págs. München.

CAPPETTA, H. \& NOLF, D., 1991: Les selaciens du Pliocene Inferieur de Le-PugetSurArgens (Sud-Est de la France).Paleontolgraphica Abt. A. 218: 49-67.

CARPENTER, K.E., 2002: Sparidae.- En: CARPENTER, K.E. (ed.): The living marine resources of the Western Central Atlantic. Volume 3: Bony fishes part 2 (Opistognathidae to Molidae), sea turtles and marine mammals. FAO Species Identification Guide for Fishery Purposes and American Society of Ichthyologists and Herpetologists Special Publication No. 5. Rome, FAO. 2002. 1375-2127. 15541577.

CARRILLO-BRICEÑO, J.D., AGUILERA, O.A. \& RODRÍGUEZ, F., 2014: Fossil Condrichthyes from the Central Eastern Pacific Ocean and their Paleoceanographic Significance.- J. South Amer. Earth Sci. 51:76-90.

CASE, G.R., 1980: A selachian fauna from the Trent Formation, Lower Miocene (Aquitanian) of Eastern North Carolina.Palaeontographica Abt. A, 171(1-3): 75103.

CASE, G.R. \& WEST, R.M., 1991: Geology and Paleontology of the Eocene Drazinda Shale Member of the Khirthar Formation, central Western Pakistan, Part II Late Eocene fishes.- Tertiary Res. 12(3-4): 105-120. 
CASIER, E., 1958: Contribution à l'étude des poisson fossile des Antilles.- Mémoires Suisses de Paléontologie, 74: 1-95.

CASIER, E., 1966: Sur la faune ichthyologique de la Formación de Bissex Hill et de la série océanique, de l'Ile de la Barbade, et sur l'âge de ces formations.- Eclogae geologicae Helvetie, 59(1): 493-515.

CIGALA-FULGOSI, F., 1977: Heptranchias perlo (Bonaterre) (Selachii, Hexanchidae) nel Serravalliano di Visiano (Medesano, Parma, Emilia Occidentale) considerazioni tassonomiche e filogenetiche.- Boll. Soc. Paleont. Italiana, 16(2): 245-256.

CIGALA-FULGOSI, F., 1986: A deep water elasmobranch fauna from a lower Pliocene outcropping (Northern Italy).- En: UYENO, T., ARAI, R., TANIUCHI, T. \& MATSUURA, K. (eds): Proceedings of the second international conference on Indo-Pacific fishes.- Ichthyological Soc. of Japan, Tokyo, 133-139.

CIONE, A.L., 2002: An Oplegnathid beak (Osteichthyes: Perciformes) from the Early Miocene of Patagonia. Extirpation of several vertebrates from the southern Atlantic Ocean.- Geobios, 35: 367-373.

CIONE, A.L., AZPELICUETA, M., BOND, M., CARLINI, A.A., CASCIOTTA, J.R., COZZUOL, M.A., DE LA FUENTE, M., GASPARINI, Z., GOIN, F.J., NORIEGA, J., SCILLATO-YANE, G.J., SOIBELZON, L., TONNI, E.P., VERZI, D. \& VUCCETICH, M.G., 2000: Miocene vertebrates from Entre Ríos province, eastern Argentina.En: ACEÑOLAZA, F.G. \& HERBST, R. (eds): El Neógeno de Argentina.INSUGEO, Serie Correlación Geológica, 14: 191-237.
CIONE, A.L., CABRERA, D.A., AZPELICUETA, M.M., CASCIOTTA, J.R., BARLA, M.J., 2013: Peces del Mioceno Marino y Continental en Entre Ríos, Oriente central, Argentina.- En: BRANDONI, D. \& NORIEGA, J.I. (eds): El Neógeno de la Mesopotamia argentina.- Asoc. Paleont. Argentina, Pub. Esp. 14: 71-83.

CIONE, A.L., MENNUCCI, J.A., SANTALUCITA, F., \& ACOSTA HOSPITALECHE, C., 2007: Local extinction of sharks of genus Carcharias Rafinesque, 1810 (Elasmobranchii, Odontaspididae) in the eastern Pacífic Ocean.- Rev. Geol. de Chile, 34 (1): 139-145.

COMPAGNO, L.J.V., 1984a: An annotated and illustrated catalogue of shark species known to date, Part 1 - Hexanchiformes to Lamniformes.- FAO Fish. Synop. (125) 4(1): 1-250.

COMPAGNO, L.J.V., 1984b: An annotated and illustrated catalogue of shark species known to date, Part 2 - Carcharhiniformes.FAO Fish. Synop., (125) 4(2): 251- 655.

COMPAGNO, L.J.V., 2002: Sharks of the world an annotated and illustrated catalogue of shark species known to date. Volume 2: Bullhead, mackerel and carpet sharks (Heterodontiformes, Lamniformes and Orectolobiformes).- FAO Species Catalogue for Fishery Purposes, 21: 1-269 (2001).

COLLOCA, F. \& CERASI, S., 2012: Cultured aquatic species information programme. Sparus aurata.- En: FAO Fisheries and Aquaculture Department [online]. Roma. Actualizado el 8 Febrero de 2005. [Citado el 6 Agosto de 2012]. http://www.fao.org/ fishery/culturedspecies/Sparus_aurata/en 
COWMAN, P.F. \& BELLWOOD, D.R., 2011: Coral reefs as drivers of cladogenesis: expanding coral reefs, cryptic extinction events, and the development of biodiversity hotspots.- J. Evolutionary Biol. 24: 2543-2562.

COWMAN, P.F. \& BELLWOOD, D.R., 2013: The historical biogeography of coral reef fishes: global patterns of origination and dispersal.J. Biogeography, 40(2): 209-224.

DE MUIZON, C. \& DEVRIES, T.J., 1985: Geology and paleontology of Late Cenozoic marine deposit in the Sacaco Area (Perú).- Geologische Rundschau, 74(3): 547-563.

DÍAZ-FRANCO, S. \& ROJAS-CONSUEGRA, R., 2009: Dientes fósiles de Sphyraena (Perciformes: Sphyraenidae) en el Terciario de Cuba Occidental.- Solenodon, 8: 124-129.

DICA, E.P., 2002: A review of the Eocene Diodontids and Labrids from Transilvanya.- Studia Universitatis BabesBolyai.- Geologia, 47(2): 37-46.

EASTMANN, C.R., 1904: Pisces. In Miocene of Maryland, SystematicPaleontology.Maryland Geol. Survey, 71-93.

ESPINOSA-ARRUBARENA, L. \& APPLEGATE, S.P., 1981: Selacifauna Pliocénica de Baja California Sur, México y sus problemas de correlación regional.- Anales del Segundo Congreso Latinoamericano de Paleontología, Porto Alegre, Brasil, 667-681.

FERNÁNDEZ, J.A., 1987: Geología de la hoja topográfica Tucurrique (1:50 000, I.G.N.C.R., \# 3445 I).- 206 págs. Univ. de Costa Rica, San José [Tesis Lic].
FITZGERALD, E.M.G., 2004: A review of the Tertiary fossil Cetacea (Mammalia) localities in Australia.- Mem. Museum Victoria, 61(2): 183-208.

FROESE, R. \& PAULY, D. (eds.), 2013: FishBase. World Wide Web electronic publication. www.fishbase.org, version (04/2013).

GARCÍA, E.X.M., ANTUNES, M.T., CÁCERES BALBINO, A., RUÍZ MUÑOZ, F. \& CIVIS LLOVERA, J., 2009: Los tiburones Lamniformes (Chondrichthyes, Galeomorphii) del Plioceno Inferior de la Formación Arenas de Huelva, Suroeste de la Cuenca de Guadalquivir, España.- Rev. Mexicana de Cien. Geol. 26(3): 674-686.

GAUDANT, J., 2002: La crise messinienne et ses effets sur l'ichthyofaune néogène de la Méditerranée: le témoignage des squelettes en connexion de poissons téléostéens.Geodiversitas, 24(3): 691-710.

GIBBES, R.W., 1848: Monograph of the fossil Squalidae of the United States.- J. Acad. Natur. Sci. Philadelphia 2 Ser. (1): 26 pp.

GILLETTE, D.G., 1984: A marine ichthyiofauna from the Miocene of Panamá, and tertiary caribbean faunal province. - En: MACFADDEN, B.J. (ed.): Origin and evolution of the Cenozoic vertebrate fauna of Middle America. - Journal of Vertebrate Paleontology, 4(2): 172- 186 .

GINSBURG, L.; CHENEVAL, J., JANVIER, P., POUIT, D. \& SEN, S., 2000: Les Vertébrés des sables continentaux d'âge orléanien inférieur (MN 3) de Mauvières à Marcillysur-Maulne (Indre-et-Loire), La Brosse à Meigné-le-Vicomte (Maine-et-Loire).Geodiversitas, 22(4): 597-631. 
GIRONE, A., NOLF, D. \& CAVALLO, O., 2010: Fish otoliths from the pre-evaporitic Early Messinian of northern Italy: their stratigraphic and palaeobiogeographic significance.- Facies, 56:399-432.

GLÜCKMAN, L.S., 1964: Class Chondrichthyes, Subclass Elasmobranchii.- En: OBRUCHEV, D.V. (ed.): Fundamental of Paleontology, Moscow \& Leningrad (Nauka SSSR), 11: 196-237.

GONZÁLEZ-BARBA, G., 1996: Descripción de asociaciones faunísticas de condrictios en el Cenozoico de Baja California a partir del registro fósil y reciente.- 21 págs. Instituto Politécnico Nacional, Centro Interdisciplinario de Ciencia Marinas, Seminario Departamental de Pesquerías y Biología Marina. Univ. Autónoma de Baja California Sur [Proyecto Tesis M.Sc.].

GONZÁLEZ-RODRÍGUEZ, K.A, ESPINOZAARRUBARENA, L. \& GONZÁLEZBARBA, G., 2013: An overview of the Mexican fossil fish record.- En: ARRATIA, G., SCHULTZE, H.P. \& WILSON, M.V.H. (eds): Global Diversity and Evolution. Mesozoic Fishes 5: 9-34.

GREGOROVÁ, R., 2009: Diplodus sp. (Sparidae, Perciformes): a new fossil record of an articulated skeleton from Devínska Nová Ves (Upper Badenian, Vienna Basin, Slovakia).Ann. Naturhist. Mus. Wien. 111A: 313-322.

GRIJALBA BENDECK, M. \& ACEVEDO, K., 2009: Mitsukurina owstoni, Jordan (Chondrichthyes: Mitsukurinidae) Primer registro para el Caribe Colombiano.- Bol. Invest. Marinas y Costeras, 38(1): 211-215.

GUSSONE, N., EISENHAUER, A., TIEDEMANN, R., HAUG, G., HEUSER, A., BOCK, B., NÄGLER, T.F., \& MÜLLER, A., 2004: Reconstruction of
Caribbean Sea surface temperature and salinity fluctuations in response to the Pliocene closure of the Central American Gateway and radiative forcing, using $\delta 44 / 40 \mathrm{Ca}, \delta 18 \mathrm{O}$ and $\mathrm{Mg} / \mathrm{Ca}$ ratios.- Earth and Planetary Sci. Letters, 227: 201-214.

ITOIGAWA, J. \& NISHIMOTO, H., 1974: Fossil elasmobranchs (shark teeth) from the Miocene series of Mizunami.- Bull. Mizunami Fossil Mus. 1: 243-262.

ITURRALDE-VINENT, M., HUBBELL, G. \& ROJAS, R., 1996: Catalogue of Cuban fossil Elasmobranchii (Paleocene to Pliocene) and paleogeographic implications of their Lower to Middle Miocene occurrence.- J. Geol. Soc. Jamaica, 31: 7-21.

JONET, S., 1975: Notes d'ichthyologie Miocene Portugaise.- Bol. Sociedade Geológica de Portugal, 29(3): 135-173.

JONET, S., KOTCHETOFF, Y. \& KOTCHETOFF, B., 1975: L'Helvetien du Penedo et la faune Ichthyologique.- Comunic. Ser. Geol. Portugal, 49: 193-228.

KEMP, N.R., 1991: Chondricthyans in the Cretaceous and Tertiary of Australia. En: VICKERS-RICH, P., MONAGHAN, J.M. \& RICH, T.H. (eds): Vertebrate Paleontology of Australia. Capítulo 15: 497-568.

KENSLEY, B., 1985: The Faunal Deposits of a Late Pleistocene Raised Beach at Milnerton, Cape Province, South Africa.An. of the South African Mus. 95(2): 111-122.

KUGA, N., 1985: A note on faunal succession of the Tertiary elasmobranchs in Japan.The Association for the Geological Collaboration in Japan, Monograph, 30: 37-44. 
KRUCKOW, TH., 1975: Haifisch-Zähne als präkolumbianische Werkzeuge aus Costa Rica (Mittelamerika) und Nordamerika.Jb. Wittheit Bremen, 19: 191-197.

KRUCKOW, TH. \& THIES, T., 1990: Die Neoselachier der Paläokaribik (Pisces: Elasmobranchii).- Cour. Forsch. Inst. Senckenberg, 119: 1-102.

LANDINI, W., 1977: Revisione degli “Ittiodontoliti pliocenici” della collezione Lawley.Paleontogr. Ital. 70 (n.s. 40): 92-134.

LAST, P. \& STEVENS, J., 1994: Sharks and rays of Australia.- 513 págs. CSIRO, Melbourne, Australia.

LAURITO, C.A., 1999: Los seláceos fósiles de la localidad de Alto Guayacán (y otros ictiolitos asociados), Mioceno Superior Plioceno Inferior de la Formación Uscari, provincia de Limón, Costa Rica.- 168 págs. Laurito, C. (ed.), San José.

LAURITO, C.A., 2004: Ictiofauna de la Formación Punta Judas, Mioceno Medio, Provincia de Puntarenas, Costa Rica.Brenesia, 62: 57-74.

LAURITO, C.A. \& VALERIO, A.L., 2008: Ictiofauna de la localidad de San Gerardo de Limoncito, Formación Curré, Mioceno Superior, cantón de Coto Brus, provincia de Puntarenas, Costa Rica.- Rev. Geol. Amér. Central, 39: 65-85.

LAURITO, C.A., VALERIO, A.L., HERNANDEZ, A.C \& OVARES, E., 2011: Primer registro de un cetáceo fósil (Mammalia, Cetacea, Odontoceti, Squalodontidae) en la Formación Río
Banano, Mioceno Medio de Costa Rica, América Central.- Rev. Geol. Amér. Central, 44: 153-156.

LAURITO, C.A., VALERIO, A.L., OVARES, E., HERNANDEZ, A.C. \& PIZARRO, D., 2008: Peces fósiles de la localidad Lomas de Siquirres, cauce del río Reventazón, Formación Río Banano, Mioceno Superior, provincia de Limón, Costa Rica.- Rev. Geol. Amér. Central, 39: 11-25.

LERICHE, M., 1910: Sur quelques poissons du Crétacé du Bassin de Paris, Note sur les poissons Néogenes de la Catalogne.- Bull. Soc. Géol. France, 4 sér. X: 471-474.

LERICHE, M., 1927: Les Poissons de la molasse suisse. Deuxieme fascicule.- Mem. Soc. Paléontol. Suisse, 47: 57-119.

LERICHE, M., 1938: Contribution à l'etude des Poissons fossiles des pays riverains de la Méditerranée américaine (Venezuela, Trinité, Antilles, Mexique).- Mem. Soc. Paléontol. Suisse, 59: 1-48.

LERICHE, M., 1942: Contribution a l'etude des faunes ichthyologiques marines des terrains tertiaires de la plaine cotiere Atlantique et du centre des Etats-Unis. - Mem. Soc. Geol. France (Nouvelle Serie), 45: 1-111

LERICHE, M., 1957: Les Poissons néogènes de la Bretagne de l'Anjou et de la Touraine.Mém. Soc.Géol. France, N.Ser. 81: 64.

LONG, D.J., 1993: Preliminary list of the marine fishes and other vertebrate remains from the Late Pleistocene Palos Verdes Sand Formation at Costa Mesa, Orange County, California.- PaleoBios, 15: 9-13. 
LONGBOTTOM, A.E., 1979: Miocene sharks' teeth from Ecuador.- Bull. British Mus. Nat. Hist. (Geol.) 32(1): 57-70.

MARSILI, S., 2007: Pliocene Elasmobranchs in the collection of the "Museo Civico Giuseppe Scarabelli»» of Imola (Pisces Chondrichthyes Neoselachii).- Quad. Studi Nat. Romagna, 24: 19-36.

MARSILI, S., CARNEVALE, G., DANESE, E., BIANUCCI, G. \& LANDINI, W., 2007: Early Miocene vertebrates from Montagna della Maiella, Italy.- An. Paléontologie, 93: 27-66.

MATSUURA, K., 2001: Balistidae.- En: CARPENTER, K.E. \& NIEM, V.H. (eds): FAO species identification guide for fishery purposes. The living marine resources of the Western Central Pacific.- Bony fishes part 4 (Labridae to Latimeriidae), estuarine crocodiles, sea turtles, sea snakes and marine mammals. Roma, 6: 3911-3928.

MEHROTRA, D.K., 1981: Micro Teleost remains from the Miocene of India.- J. Paleont. Soc. India, 25:76-84.

MEHROTRA, D.K., 1984: Additional Fossil Fishes from Mizoram, Newsletter, Geol. Surv.- India (NER) 3: 22.

MENESINI, E., 1968: Osservazioni su Coronula bifida Bronn. - Atti della Società Toscana di Scienze Naturali Memorie, 75: 387-398.

MENESINI, E., 1969: Ittiodontoliti Miocenici di Terra d'Otranto (Puglia). - Paleontograf. Italica, 65(n.ser., 35): 1-61.

MERLE, D., BAUT, J.P., GINSBURG, L., SAGNE, C., HERVET, S., CARRIOL,
R.P., VENEC-PEYRE, M.T., BLANCVALLERON, M.M., MOURERCHAUVIRE, C., ARAMBOL, D. \& VIETTE, P., 2002: Découverte d'une faune de vertébrés dans l'Oligocène inférieur de Vayres-sur-Essonne (bassin de Paris, France): biodiversité et paléoenvironnement.- C. R. Palevol. 1: 111-116.

MÜLLER, A., 1992 : Eine Ichthyofaunen aus dem Atlantischen Tertiär der USA. Systematik Paläeoökologie, Biostratigraphie, Evolution und Paläobiogeographie. Habilitationschrift im Fachbereich Geowissenschaften der Westälischen Wilhems. Universtät Münster.- Leipziger Geowissenschaften Band 9/10, 360 pp.

NOLF, D., 1988: Dents de Requins et Raies du Tertiaire de la Belgique.- 184 págs. Ed. de l'Institut Royal des Sciences naturelles de Belgique.

NOLF, D. \& STRINGER, G.L., 1992: Neogene paleontology in the Northern Dominican Republic. Otoliths of teleostean fishes.Bull. Amer. Paleontol. 102: 41-81.

PARSONS, G.R., INGRAM, G.W. \& HAVARD, R., 2002: First record of the goblin shark Mitsukurina owstoni, Jordan (Family Mitsukurinidae) in the Gulf of Mexico.- Southeastern Naturalist, 1(2): 189-192.

PAWLOWSKA, K., 1960: Szczatki ryb z wapieni Miocenski Pinczowa.- Acta Paleontologica Polonica, 5 (4): 421- 437.

PEREA, D. \& UBILLA, M., 1989: Selacifauna del Mioceno Superior del Uruguay.- Bol. Soc. Zool. Uruguay (2 época), 5: 11-12. 
PHILLIPS, F.J., WELTON, B. \& WELTON, J., 1976: Paleontologic studies of the middle Tertiary Skooner Gulch and Gallaway formations at Point Arena, California.- Proc. Soc.. Econ. Paleontol. Mineral., Pacific Sect., Tulsa, Oklahoma, 137-154.

PIMIENTO, C., GONZALEZ-BARBA, G., HENDY, A.J.W., JARAMILLO, C., MACFADDEN, B.J., MONTES, C., SUAREZ, S.C. \& SHIPPRITT, M., 2013a: Early Miocene chondrichthyans from the Culebra Formation, Panama: A window into marine vertebrate faunas before closure the Central American Seaway.- J. South Amer. Earth Sci. 42: 159-170.

PIMIENTO,C., GONZALEZ-BARBA, G.,EHRET, D.J., HENDY, A.J.W., MACFADDEN, B.J. \& JARAMILLO, C., 2013b: Sharks and rays (Chondrichthyes, Elasmobranchii) from the Late Miocene Gatun Formation of Panama.J. Paleontol. 87(5): 755-774.

PLEDGE, N.S., 1967: Fossil Slasmobranch teeth of South Australia and their stratigraphic distribution.- Trans. Roy. Soc. South Australia, 91: 135-160.

PLEDGE, N.S., 1985: An early Pliocene shark tooth assemblage in South Australia.South Australia Department of Mines and Energy, Special Publication, 5: 287-299.

PORTELL, R.W., HUBBELL, G., DONOVAN, S.K., GREEN, J.L., HARPER, D.A. \& PICKERILL, R., 2008: Miocene sharks in the Kendeace and Grand Bay formations of Carriacou, The Grenadines, Lesser Antilles.- Caribbean J. Sci. 44(3): 279-286.

PROBST, J., 1879: Beiträge zur Kenntniss der fossilen Fische aus der Molasse von Baltringen. Hayfische.- Jh. Ver. Vaterländ. Naturkde. Württemberg, 35: 127-191.
PURDY, R.W., SCHNEIDER, V.P., APPLEGATE, S.P., MCLELLAN, J.H., MEYER, R.L., \& SLAUGHTER, B.H., 2001: The Neogene Shark, Ray, and Bony Fishes from Lee Creek Mine, Aurora North Carolina. - En: RAY, C.E. \& BOHASKA, D.J. (eds.): Geology and Paleontology of the Lee Creek Mine, North Carolina, III.Smithsonian Contribution to Paleobiol. 90: 71-202.

RALTE, V.Z., TIWARI, R.P.,LALCHAWIMAWII, H. \& MALSAUMA, J., 2011: Selachian Fishes from Bhuban Formation, Surma Group, Aizawl, Mizoram.- J. Geol. Soc. India, 77: 328-348.

RANDALL, J.E., 2001: Acanthuridae: Surgeonfishes (tangs, unicornfishes). En: CARPENTER, K.E. \& NIEM, V.H. (eds): FAO species identification guide for fishery purposes. The living marine resources of the Western Central Pacific. Volume 6. Bony fishes part 4 (Labridae to Latimeriidae), estuarine crocodiles, sea turtles, sea snakes and marine mammals. Roma, FAO: 36533672 .

REINECKE, T., STAPF, H. \& RAISCH, M., 2001: Die Selachier und Chimären des Unteren Meeressandes un Schleichsandes im Mainzer Becken (Rupelium, Unteres Oligozän).- Paleontos $1:$ 1-173.

ROUX, C. \& GEISTODOERFER, P., 1988: Dents de requins et bulles tympaniques de cetaces: Noyaux de nodules polymetalliques recoltes dans L'Ocean Indien.- Cybium, 12(2): 129-137.

SAHNI, A. \& MEHROTRA, D.K., 1981: The Elasmobranch fauna of coastal Miocene sediments of Peninsular India.- Biol. Mem. 5(2): 83-121. 
SÁNCHEZ-VILLAGRA, M.R. \& AGUILERA, O.A., 2006: Neogene vertebrates from Urumaco, Falcón State, Venezuela: Diversity and significance.- J. Systematic Palaeont. 4(3): 213-220.

SCHULTZ, O., 1968: Die selachierfauna (Pisces, Elasmobranchii) aus den Phosphoritsanden (Unter-Miozän) von Plesching bei Linz Oberösterreich.- Naturkundliches Jahrbuch der Stadt Linz, 14: 61-102.

SCHULTZ, O., 1969: Die Selachierfauna (Pisces, Elasmobranchii) aus den Phosphoritsanden (Unter-Miozän) von Plesching bei Linz, Oberösterreich.Naturkundliche.- Jahrbuch der Stadt Linz, 14(1968): 61-102.

SCHULTZ, O., 1978: Neue und fehlinterpretierte Fischformen aus dem Miozän dês Wiener Beckens.- Ann. Naturhist. Mus. Wien, 81: 203-219.

SCHULTZ, O., 2001: Ein Zackenbarsch (Epinephelus, Serranidae, Pisces) aus dem Mittel-Miozän von Retznei, Steiermark.Joannea Geologie und Paläontologie, 2: 5-56.

SCHULTZ, O. \& BELLWOOD, D.R., 2004: Trigonodon oweni and Asima jugleri are different parts of the same species Trigonodon jugleri, a Chiseltooth Wrasse from the Lower and Middle Miocene in Central Europe (Osteichthyes, Labridae, Trigonodontinae). - Ann. Naturhist. Mus. Wien, 105 A: 287-305.

SERRALHEIRO, R., 1954: Contribução para o conhecimento da fauna ictiológica do miocéno marinho de Portugal Continental.- Rev. Faculd. Ciênc. de Lisboa, C, 4(1): 39-119.
SEYFRIED, H., SPRECHMANN, P. \& AGUILAR, T., 1985: Sedimentología y paleoecología de un estuario del litoral Pacífico del Istmo Centroamericano primordial (Mioceno Medio, Costa Rica).Rev. Geol. Amér. Central, 3: 1-68.

SISMONDA, E., 1861: Appendice alla descrizione dei pesci e dei crostacei fossili del Piemonte.- Memorie della Regia Accademia delle Scienze di Torino, 19: 453-474.

STRINGER, G.L., 1998: Otolith-based fishes from the Bowden shell bed (Pliocene) of Jamaica: systematic and palaeoecology.Contr. Tert. Quatern. Geol. 35(1-4): 147160.

SUAREZ, M.E., ENCINAS, A. \& WARD, D., 2006: An Early Miocene elasmobranch fauna from the Navidad Formation, Central Chile, South America.- Cainozoic Research 1-2: 3-18.

TAKAKUWA, Y., 2006: A deep - sea shark assemblage from the Miocene in southwest of Gunma Prefecture, central Japan and the biogeographical significance.- Fossils, Paleont. Soc. Japan, 81: 24-44.

TAYLOR, G.D., 1975: The Geology of the Limon area of Costa Rica.- 116 págs. Louisiana State Univ. and Agricultural and Mechanical College. Louisiana [Tesis Ph.D].

TOULA, F., 1909: Eine jungertiäre Fauna von Gatun am Panama-Kanal.- Jahrb. Geol. Reichsanstalt, 58 (4): 673-760.

UGORETZ, J. \& SIEGEL, J., 1999: First eastern Pacific record of the goblin shark, Mitsukurina owstoni (Lamniformes: Mitsukurinidae).- Cal. Fish Game, 85(3): 118-120. 
UYENO, T. \& MATSUSHIMA, Y., 1974: Early Pleistocene remains of basking sharks, hammerhead shark, and others found in Yokohama, Japan.- Bull. Kanagawa Pref. Mus. 7: 57-66.

VAELLO I APARICIO, M., 1989: Contribució al coneixement de la fauna ictiológica del Miocé Tarragoní.- Bull. Cent. Est. Nat. Barcelona Nord. 5: 212-218.

VIALLE, N., ADNET, S. \& CAPPETTA, H., 2011: A new shark and ray fauna from the Middle Miocene of Mazan, Vaucluse (southern France) and its importance in interpreting the paleoenvironment of marine deposits in the southern Rhodanian Basin.- Swiss J. Palaeontol. 130: 241-258.

VICENS, D. \& RODRIGUEZ-PEREA, A., 2003: Vertebrats fossils (Pisces i Reptilia) del burdi- galia de cala Sant Vicenç (Pollenca, Mallorca).Boll. Soc. Hist. Nat. Balears, 46: 117-130.

WARD, D.J. \& BONAVIA, C., 2001: Additions to, and a review of, the Miocene shark and ray fauna of Malta.- The Central Mediterranean Naturalist, 3: 131-146.

WHITE, E.I., 1955: On Lamna Eurybathrodon Blake.- An. Magazine Natural History, 8: 191-193.

YABE, H. \& HIRAYAMA, R., 1998: Selachian fauna from the Upper Miocene Senhata Formation, Boso Peninsula, Central Japan.- Natural History Research, Special Issue, 5: 33-61.

ZBYSZEWSKI, G. \& MOITINHO D'ALMEIDA, F., 1950: Os peixes miocénicos portugueses.- Comunicaçôes dos Serviços Geológicos de Portugal, 31: 309-412. 